\title{
The microstructure of meteoric ice from Vostok, Antarctica
}

\author{
Rachel OBBARD, Ian BAKER \\ Thayer School of Engineering, Dartmouth College, Hanover, New Hampshire 03755-8000, USA \\ E-mail: rachel.w.obbard@dartmouth.edu
}

\begin{abstract}
The $3623 \mathrm{~m}$ long, 5G core collected at Vostok station, Antarctica, contains alternating layers of meteoric ice with two distinctly different microstructures. In this paper, we present the microstructure and impurity content of a number of specimens ranging in depth from 97 to $3416 \mathrm{~m}$, describe in detail the characteristics of the different layers and propose a mechanism for their microstructural development. Digital image analysis, ion chromatography, scanning electron microscopy and energy dispersive $\mathrm{X}$-ray spectroscopy were used to measure texture and the location and type of impurities; electron backscatter diffraction was used to determine crystal orientation. The ice associated with interglacial periods is characterized by relatively coarse grains and a strong preferred orientation of the $c$ axes in a plane encompassing the coring direction, producing a vertical-girdle fabric. In contrast, ice from glacial periods is characterized by a much smaller grain size and a strong singlemaximum fabric, where the $c$ axes are clustered around the vertical. Calcium is uniquely present in the grain boundaries of the fine-grained glacial layers, and its effect on grain-boundary mobility and the misorientation dependence of mobility can explain the development of the discontinuous microstructure seen in glacial ice at Vostok station.
\end{abstract}

\section{INTRODUCTION AND BACKGROUND}

The subject of this paper is ice from Vostok core 5G, which was obtained at the Russian Vostok station in East Antarctica $\left(78^{\circ} 28^{\prime} \mathrm{S}, 106^{\circ} 48^{\prime} \mathrm{E}\right)$ through collaboration between Russia, France, and the United States. The coring reached a depth of $3623 \mathrm{~m}$ in January 1998. The altitude is $3488 \mathrm{~m}$ a.s.I., the present-day mean air temperature at the surface is $-55.5^{\circ} \mathrm{C}$ and the annual accumulation is $2.2-2.5 \mathrm{~g} \mathrm{~cm}^{-2}$ (Jouzel and others, 1987; Lipenkov and others, 1989; Salamatin and others, 1998).

The Vostok core is important because it contains ice formed under unique circumstances. It differs from other cores, even in Antarctica, due to the cold, dry local climate, the distance from the divide $(120 \mathrm{~km})$, and a low surface slope $\left(1 \times 10^{-3} \mathrm{~m} \mathrm{~m}^{-1}\right)$ but with a significant $\left(3 \mathrm{~m} \mathrm{a}^{-1}\right)$ horizontal flow. For example, it is estimated that at $2083 \mathrm{~m}$, where the temperature is $-36^{\circ} \mathrm{C}$, the vertical strain rate is $7 \times 10^{-6} \mathrm{a}^{-1}$, the horizontal shear stress at $2000 \mathrm{~m}$ is $<20 \mathrm{kPa}$ and the shear strain rate is approximately $4 \times 10^{-6} \mathrm{a}^{-1}$ (Lipenkov and others, 1989; Salamatin and others, 1998). The fabric and texture of the initial $2083 \mathrm{~m}$ of the core is described in Lipenkov and others (1989). The authors found that the crystal growth rate is lower during the cold periods, identified from the oxygen isotope $\delta^{18} \mathrm{O}$ record as 1330 kyr BP (about 300-500 m) and 140-160 kyr BP (about 1900-2083 m), than in warm periods that include the past 13 kyr BP (shallower than $300 \mathrm{~m}$ ) and 116-140 kyr BP (1600$1900 \mathrm{~m})$. They also noted that crystal shape becomes elongated in a horizontal direction below $100 \mathrm{~m}$, changing most between 350 and $500 \mathrm{~m}$. Crystal orientation is initially quasi-uniformly distributed, but beginning at about $454 \mathrm{~m}$ assumes a vertical-girdle nature where the direction of grain elongation is nearly orthogonal to the vertical plane containing the $c$ axes. This is important because it demonstrates that the ice at this location is deformed both from basal glide brought on by compression and from horizontal tension. The vertical-girdle fabric persists in the remainder of their pole figure to $2083 \mathrm{~m}$, i.e. the fabric does not vary with temperature $\left(\delta^{18} \mathrm{O}\right)$ (Lipenkov and others, 1989).

Dating and paleoclimatic interpretations of the isotopic record in the deep borehole (below $1800 \mathrm{~m}$ ) were presented by Salamatin and others (1998), the result of a comparison and reconciliation of data from four different temperature profile analyses conducted between 1988 and 1998.

Grain-size, deuterium profile and seismic wave-speed measurements for the deeper parts of the core were presented by Lipenkov and Barkov at an international workshop in St Petersburg in 1998 (Lipenkov and Barkov, 1998). The figure from their abstract, reproduced as Figure 1 without change to the figure or caption, describes an internal structure characterized by zones of markedly different texture and fabric, beginning most noticeably at $2700 \mathrm{~m}$. Two distinct microstructures, categorized as A and B zones, alternate. A-type zones, which include, but are not strictly limited to, warmer interglacial periods, are characterized by larger grains with a vertical-girdle orientation, i.e. their $c$ axes fall in a plane encompassing the vertical. The vertical-girdle fabric arises from the rotation of grains by basal glide under conditions of vertical compression coupled with uniaxial tension in the direction of flow (Lipenkov and others, 1989; Paterson, 1991). Castelnau and others (1997) developed a model that assumes uniform stress and strain within each grain of ice, and deformation primarily by basal slip. When De La Chappelle and others (1998) applied this visco-plastic self-consistent (VPSC) model to simulate the development of the vertical-girdle fabric at Vostok, it produced a far tighter girdle than is actually found there. They attributed this difference to polygonization. In nature, grains with $c$ axes already parallel to the direction of compression cannot deform by basal glide: axial stresses parallel and perpendicular to the $c$ axis grow and bending moments appear. This leads to competition between lattice rotation by basal slip and polygonization. Polygonization is defined as the process whereby further strain, after a strong preferred fabric has developed, 


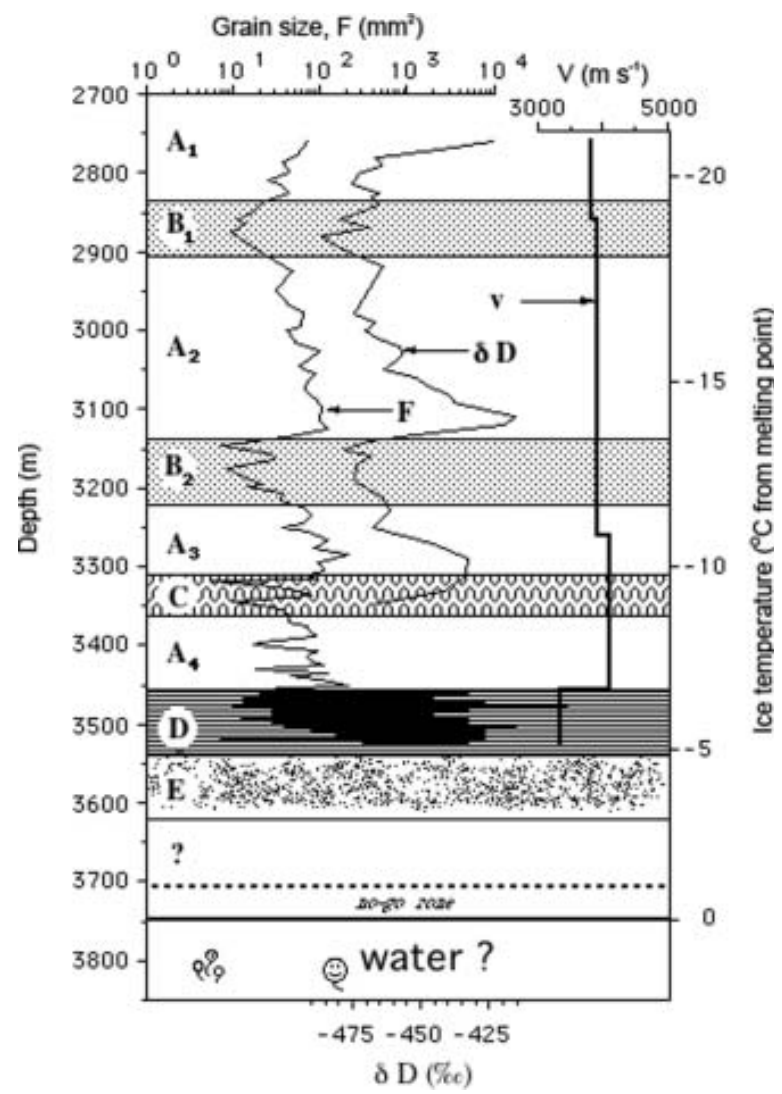

Fig. 1. Internal structure of the Antarctic ice sheet at Vostok station (2700-3623 mbs) (Lipenkov and Barkov, 1998). Reprinted with permission of the authors. $A_{1-4}$ Zones of relatively coarse-grained ice with girdle-type fabric corresponding to uniaxial extension of ice along flow line; $B_{1,2}$ Zones of relatively fine-grained ice with single-maximum fabric corresponding to shear; zones B coincide with the ice strata formed under conditions of glacial maxima (high impurity concentration); C Former zone of ice-flow disturbance (?); D Layered ice stratum interpreted as a sole of the moving section of the ice sheet; E Basal ultra-coarse-grained silty ice considered as stagnant ice. Remarkable correlation between the grain-size $\left(\mathrm{F}, \mathrm{mm}^{2}\right)$ and the deuterium profile $(\delta \mathrm{D}, \%)$ (Petit and others, 1998) indicates the link between the internal structure of the ice sheet and climate. Vertical profile of seismic wave speed $(\nu, \mathrm{m} / \mathrm{s}$ ) (Popkov and others, 1999) exhibits significant decrease in $\nu$ within stratum D.

causes the alignment of dislocations within grains and the subsequent formation of sub-grain boundaries and additional new grains that differ in orientation from the $c$ axis of the original grain by only a few degrees.

In contrast, B-type zones, which coincide with cold conditions and glacial maxima (Lipenkov and others, 1989; Lipenkov and Barkov, 1998; personal communication from V. Lipenkov, 2005), have higher impurity concentrations, smaller average grain sizes and a single-maximum fabric. A single-maximum fabric is usually produced by vertical compression (and divergent horizontal tension) (Azuma and Higashi, 1985) or by simple shear near the base of a glacier (Budd and Jacka, 1989). The authors noted that these different fabrics (single maximum and vertical girdle) are characteristic of different stress conditions, and suggested that their interpretation requires an assumption of discontinuity in the recrystallization and deformation processes that may be attributed to structural softening.

After the first two alternating $A$ and $B$ zones, the third interglacial zone, $A_{3}$, is followed by a zone labelled $C$
(3310-3370 m) (see Fig. 1), which contains evidence of stratigraphic disturbance. At $3311 \mathrm{~m}$, there are three ash layers a few centimeters apart but sloping in opposite directions (Petit and others, 1999). At $3321 \mathrm{~m}$, there is a shift in deuterium content from interglacial-like to glacial-like conditions and then back again, accompanied by a transition in $\mathrm{CO}_{2}$ and $\mathrm{CH}_{4}$ gas levels from glacial-like (low) to interglacial-like (high) conditions (Petit and others, 1999). The gas transition associated with a change from glacial to interglacial conditions would normally be expected somewhat deeper $(\sim 10 \mathrm{~m})$ (Petit and others, 1999). These features have led some to conclude that the $\mathrm{C}$ zone has undergone folding (Petit and others, 1999; Simões and others, 2002). Interestingly, it was concluded that deeper ice (3370$3538 \mathrm{~m}$ ) was undisturbed, based on the lack of structural incongruities and the observation that air hydrate crystals there exhibited uninterrupted growth with depth (Simões and others, 2002). A fourth A-type zone, $\mathrm{A}_{4}$ (Fig. 1), found from 3370 to $3460 \mathrm{~m}$, is followed by zone D (3460-3538 m), the main shear layer of the moving ice sheet, which is characterized by rapidly alternating A- and B-type layers. At the bottom of the meteoric ice lies zone E (3538-3605 m), which consists of very coarse-grained silty basal ice. The last $17 \mathrm{~m}$ of the core are accretion ice, formed by melting and refreezing as the glacier passes over Vostok Subglacial Lake. Drilling ceased at $3623 \mathrm{~m}$, approximately $100 \mathrm{~m}$ above the subglacial lake.

Early attempts to date the Vostok core using gas isotope data (Petit and others, 1999) ended at $3310 \mathrm{~m}$ because of the discontinuity in the climate record noted at $3311 \mathrm{~m}$. Between 3320 and $3330 \mathrm{~m}$ an abrupt transition from interglacial to glacial deuterium $(\delta \mathrm{D}$, a proxy for local temperature) and gas $\left(\mathrm{CO}_{2}\right.$ and $\left.\mathrm{CH}_{4}\right)$ content, and then back to interglacial values, was observed. Nonetheless, recent efforts have produced dating for depths below $3350 \mathrm{~m}$ (Salamatin and others, 2004). The latter approach applies three different techniques for dating: (i) the geophysical metronome timescale (GMTS); (ii) correlation of the Vostok ice-core deuterium-depth signal with a second independent oxygen-isotope $\left(\delta^{18} \mathrm{O}\right)$ based timescale (DHVTS, from the calcite core (DH-11) in Devils Hole, NV, USA); and (iii) iceflow modeling fitted to both the GMTS and DHVTS. Despite the stratigraphic disturbance reported at $3311 \mathrm{~m}$ (Petit and others, 1999), Simões and others (2002) have shown that glacial stages 14 and 16 are still distinctly discerned in the dust concentration record within the depth intervals 3393$3405 \mathrm{~m}$ and 3440-3455 m, respectively, and evidence of interglacial stage 17 appears from 3457 to $3466 \mathrm{~m}$. This suggests that strata as deep as $3466 \mathrm{~m}$ have undergone only local perturbations. Salamatin and others (2004) use their constrained ice-sheet flow model to extrapolate the mean ice age-depth curve to produce theoretical dating for the rest of the Vostok meteoric ice. This provides the depth-age scale we use in this paper.

This paper presents the microstructure and impurity content of a number of specimens ranging in depth from 97 to $3416 \mathrm{~m}$, describes in detail the characteristics of different layers and proposes a mechanism for the development of these layers.

\section{MEASUREMENT METHODS}

The Vostok $5 \mathrm{G}$ core specimens used in this study were stored at $-35^{\circ} \mathrm{C}$ for 7 years at the US National Ice Core Laboratory 
Table 1. Textural data for all Vostok samples, including the number of grains measured

\begin{tabular}{|c|c|c|c|c|c|}
\hline $\begin{array}{l}\text { Depth } \\
\text { m }\end{array}$ & $\begin{array}{c}\text { Age } \\
\text { years BP }\end{array}$ & Number of grains & $\begin{array}{c}\text { Grain area } \\
\mathrm{mm}^{2}\end{array}$ & Aspect ratio & Zone \\
\hline 97 & 3450 & 939 & 1.38 & & \\
\hline $248.15-248.19$ & 10084 & 421 & 3.71 & & \\
\hline 399 & 20160 & 988 & 1.67 & & \\
\hline $650.325-650.395$ & 39565 & 659 & 3.73 & & \\
\hline 1201 & 84322 & 184 & 6.73 & & \\
\hline 1500 & 108372 & 177 & 7.92 & & \\
\hline $1849.875-1849.915$ & 127978 & 80 & 17.96 & & \\
\hline 2082.13-2082.17 & 149231 & 217 & 12.43 & & \\
\hline 2749 & 239952 & 135 & 35.11 & 1.02 & $\mathrm{~A}_{1}$ \\
\hline 2874.49-2874.53 & 269226 & 180 & 8.29 & 2.34 & $B_{1}$ \\
\hline $3300.68-3300.72$ & 410402 & 73 & 63.85 & 1.27 & $A_{3}$ \\
\hline $3311.45-3311.49$ & 414851 & 69 & 65.63 & 1.07 & $\mathrm{C}$ \\
\hline $3321.765-3321.805$ & 420314 & 319 & 7.20 & 1.61 & $\mathrm{C}$ \\
\hline $3329.46-3329.50$ & 424589 & 93 & 55.99 & 1.24 & $\mathrm{C}$ \\
\hline 3399.66-3399.70 & Unknown & 132 & 15.84 & 1.46 & $\mathrm{~A}_{4}$ \\
\hline $3416.55-3416.56$ & Unknown & 49 & 48.31 & 1.31 & $\mathrm{~A}_{4}$ \\
\hline
\end{tabular}

Notes: Age corresponding to sample depth was determined using Salamatin and others (2004) as described in the text. Average grain size measured by pixel counting. Grain flattening is reported as aspect ratio, a comparison of average grain size perpendicular vs parallel to core, and was measured only on samples from $>2700 \mathrm{~m}$. Zones are from Lipenkov and Barkov (1998) and are described in Figure 1.

(NICL) in Denver, $\mathrm{CO}$, and later at $-25^{\circ} \mathrm{C}$ for 1 year in the Ice Research Laboratory (IRL) at the Thayer School of Engineering at Dartmouth College. The depths of the sections used for this study are shown in Table 1. These depths are from the bags of specimens retrieved from storage at NICL and shipped there from Vostok station. Depth data for a few sections are available only to the nearest meter. Herein, the section depths will be referred to by integer numbers except where greater specificity is useful and available.

\subsection{Grain size}

Vertical thin sections were prepared for grain-size measurement. Grain size (area) was measured using two different methods. First, we used the standard linear intercept method (Alley and Woods, 1996; Gow and others, 1997) (200 intercepts obtained for each depth). Second, we used the pixel-counting area measurement utility of an image-processing application, Image SXM (W.S. Rasband, http://rsb.info.nih.gov/ij; S.D. Barrett, http://www.liv.ac.uk/ $\sim \mathrm{sdb} /$ ImageSXM). For larger-grained specimens, multiple thin sections were analyzed with Image SXM so that at least 100 grains were measured for each depth, and over 600 grains for each specimen from $<1200 \mathrm{~m}$. The two methods yielded results that were within $7-28 \%$ of one another, but for accuracy and consistency, the pixel-counting data are used for the grain area reported (Table 1). Linear intercept data were used to calculate flattening, where aspect ratio is the average grain width divided by the average grain height.

\subsection{Ion chromatography}

A Dionex DX-120 ion chromatograph with Dionex IonPac AG14 + AS14 anion columns and CG12A + CS12A cation columns was used to gather ion concentration data in our samples. The flow rate was $1.6 \mathrm{~mL} \mathrm{~min}^{-1}$ and the pressure was approximately $11.86 \mathrm{MPa}$. The eluent was $3.5 \mathrm{mmol} \mathrm{L}^{-1}$ sodium carbonate $/ 1.0 \mathrm{mmol} \mathrm{L}^{-1}$ sodium bicarbonate. The instrument detection limits (IDL) for anions were 5-20 ppb $\mathrm{Cl}^{-}, 20-30 \mathrm{ppb} \mathrm{NO}_{3}{ }^{-}$and $20-40 \mathrm{ppb} \mathrm{SO}_{4}{ }^{2-}$. For cations, the
IDL were 1 ppb Na ${ }^{+}, 1$ ppb $\mathrm{NH}_{4}{ }^{+}, 2 \mathrm{ppb} \mathrm{K}^{+}, 8 \mathrm{ppb} \mathrm{Mg}^{2+}$ and $15 \mathrm{ppb} \mathrm{Ca}{ }^{+}$. The instrument was calibrated using a quadratic fit of six standards with the calibration curve forced through zero. Calibration verification samples were run at the middle and end of each run. Midway through the cation run, it was found that the instrument had drifted upward such that it biased the results $20 \%$ high. The order of samples run through the cation column was 2874, 3399, 3329, 2749, 3311, 3321, 399, 1849 and $650 \mathrm{~m}$, and the calibration sample was run after the specimen from $2749 \mathrm{~m}$.

The chromatograph required $5 \mathrm{~mL}$ of each sample for each run. This was obtained by cutting a piece of the specimen that was approximately $1.5 \mathrm{~cm} \times 2.0 \mathrm{~cm} \times 2.0 \mathrm{~cm}$ with a small bandsaw, then shaving the six sides of the piece with a razor blade under a HEPA (High Efficiency Particle Air)-filtered laminar-flow hood, handling the sample only with tweezers and a spatula. All tools used during specimen preparation were carefully pre-cleaned using acetone, methanol, $n$-hexane and deionized water.

Samples were melted in clean plastic sample bottles and were tested using the anion column. Repeatability was assessed by additional testing conducted later on separate samples from some depths. The cation column was acquired more recently and, due to time and limited sample availability, only certain core depths were tested and only one test was run on each.

\subsection{Scanning electron microscopy/energy-dispersive spectroscopy}

Our technique for scanning electron microscopy (SEM) and energy-dispersive spectroscopy (EDS) of uncoated ice has already been described in detail (Cullen and Baker, 2000, 2001; Baker and others, 2003). Samples approximately $2.5 \mathrm{~cm} \times 2.5 \mathrm{~cm} \times 1.0 \mathrm{~cm}$ were cut and their surfaces were shaved flat with a razor blade. The sample was frozen onto a brass plate and placed in a sealed container at $-25^{\circ} \mathrm{C}$ for approximately 24 hours. While in the scanning electron microscope, the samples were held at $-85 \pm 5^{\circ} \mathrm{C}$. 

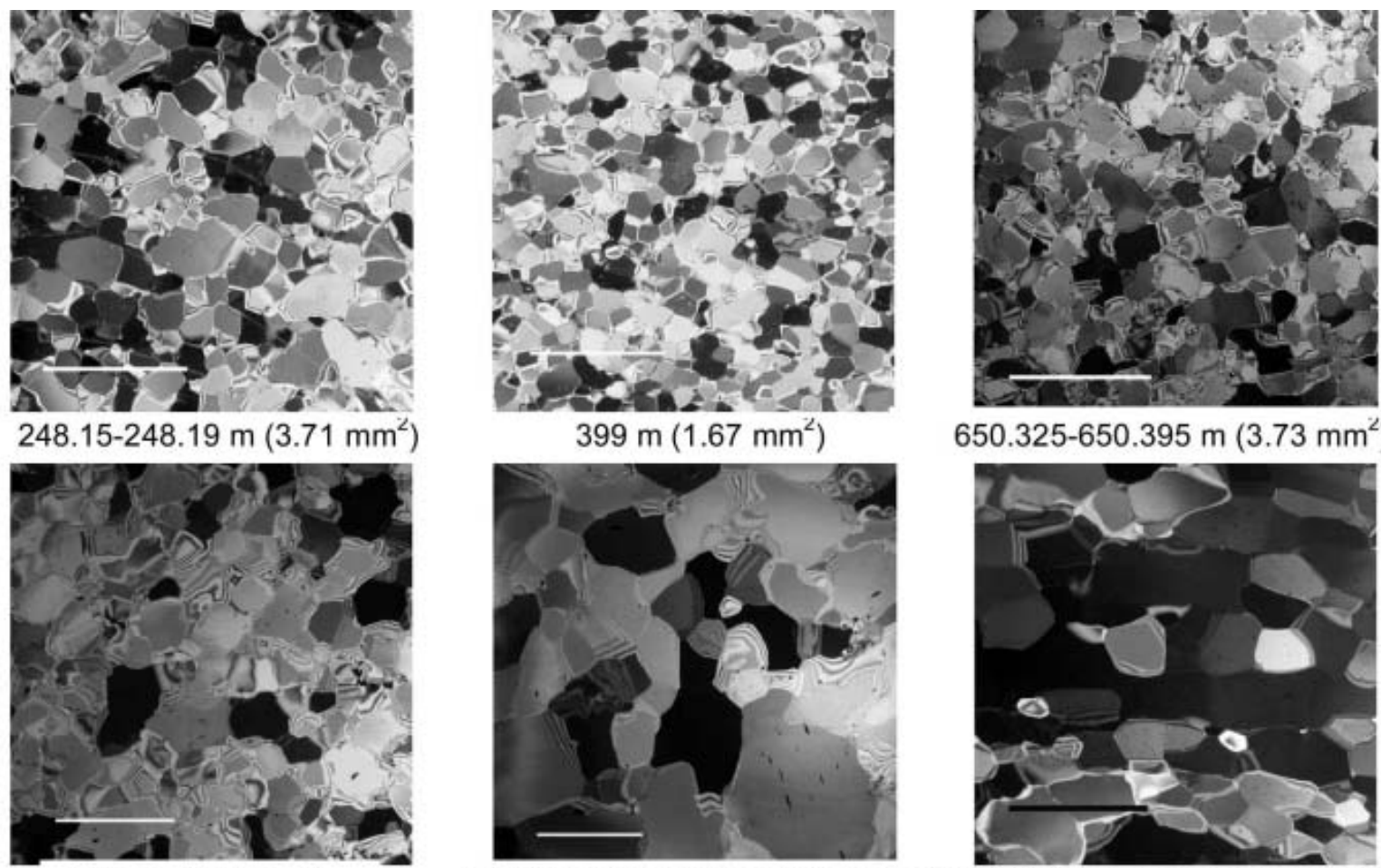

$650.325-650.395 \mathrm{~m}\left(3.73 \mathrm{~mm}^{2}\right)$

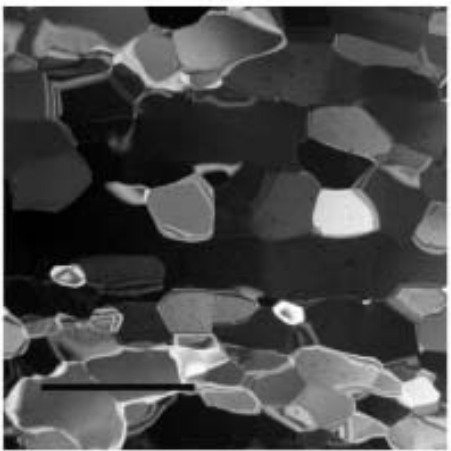

$1201 \mathrm{~m}\left(6.73 \mathrm{~mm}^{2}\right)$

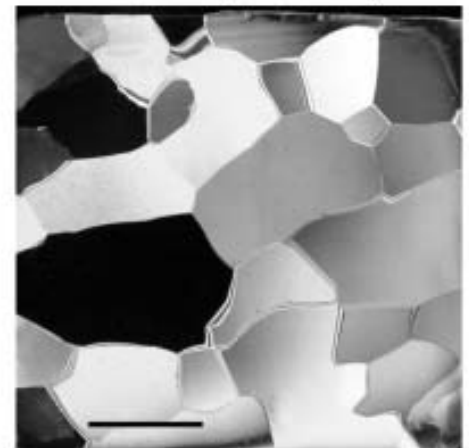

$1849.875-1849.915 \mathrm{~m}\left(17.96 \mathrm{~mm}^{2}\right)$

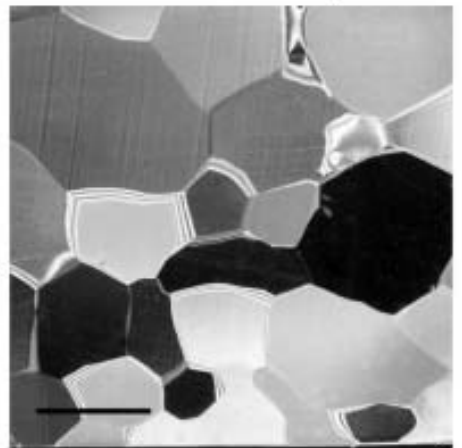

$2874.49-2874.53 \mathrm{~m}\left(8.29 \mathrm{~mm}^{2}\right)$

$3300.68-3300.72 \mathrm{~m}\left(63.85 \mathrm{~mm}^{2}\right)$
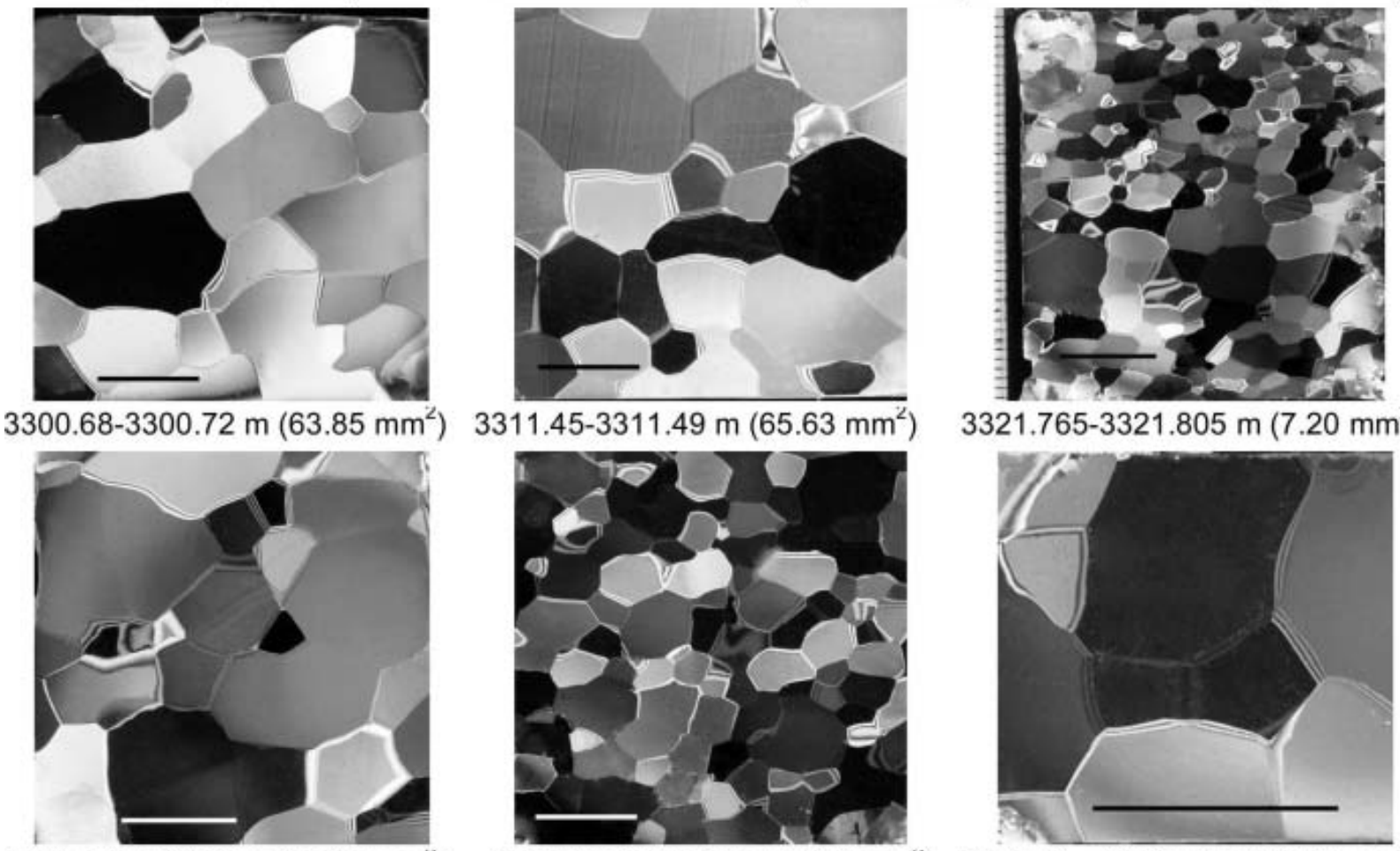

$3321.765-3321.805 \mathrm{~m}\left(7.20 \mathrm{~mm}^{2}\right)$

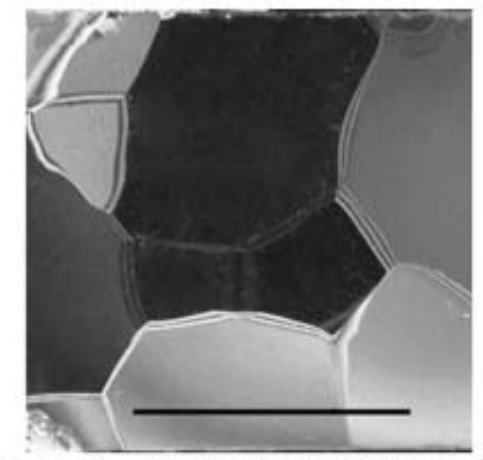

$3329.46-3329.50 \mathrm{~m}\left(55.99 \mathrm{~mm}^{2}\right)$

$3416.53-3416.56 \mathrm{~m}\left(48.31 \mathrm{~mm}^{2}\right)$

Fig. 2. Vertical thin sections (scale bars $10 \mathrm{~mm}$ ). Grain area was determined from multiple thin sections using pixel counting.

\subsection{Electron backscatter diffraction}

Uncoated ice specimens were prepared and subsequently examined in an FEI XL-30 environmental scanning electron microscope using the electron backscatter diffraction (EBSD) technique described in detail by lliescu and others (2004) and Obbard and others (2006b). Specimens with dimensions of approximately $3.0 \mathrm{~cm} \times 1.5 \mathrm{~cm} \times 3.0 \mathrm{~mm}$ were cut from core specimens such that the specimen surface lay perpendicular to the core axis. Multiple samples from the specimen were cut with the same orientation (i.e. with their long sides parallel) so that orientation data from multiple pieces of the same specimen could be plotted on a single pole figure. Other than this, there is no way of knowing the azimuthal orientation of the specimen, and differences in the direction of a vertical-girdle pattern on a pole figure are not significant.

Approximately 100 grains were measured in each sample. The measurement of more grains would have been desirable (200 is typical), but we were limited by the size of 


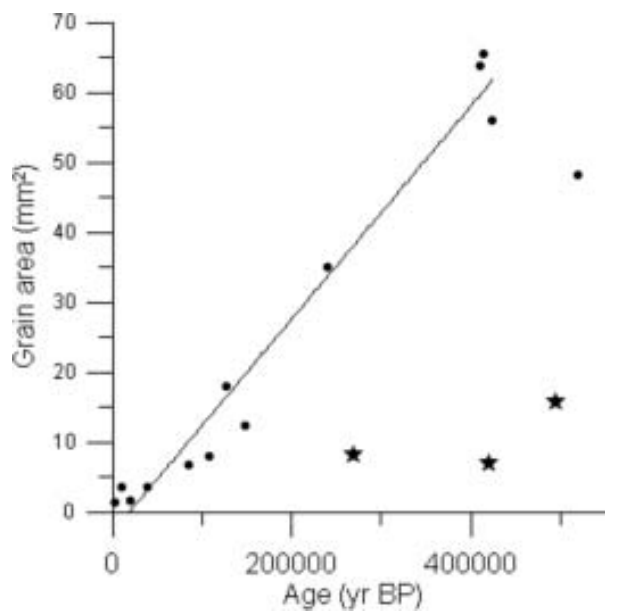

Fig. 3. Mean grain area for Vostok $5 \mathrm{G}$ as a function of age (determined using Salamatin and others, 2004) and linear fit derived as described in the text. Starred points are those identified as belonging to B-layers.

available Vostok specimens and the competing sample requirements of other analyses (e.g. ion chromatography).

Grain boundaries and triple junctions were identified visually on the specimen using the SEM imaging capabilities. Grain boundaries were identified by a clear grainboundary groove and/or a change in the surface etching pattern, the pattern of white spots on a black background that varies with lattice orientation (Obbard and others, 2006a). For each grain, a representative EBSD pattern was collected. The implied change in specimen orientation due to moving the beam across the specimen is $1.07^{\circ}$ per $2 \mathrm{~mm}$ traverse on the specimen, which is consistent with the typical $\sim 1^{\circ}$ 'orientation noise' reported by Bate and others (2005). Typically, the distance between measurements was $\leq 500 \mu \mathrm{m}$. Hence, misorientations between adjacent grains were determined to an accuracy of $\sim 0.5^{\circ}$.

The EBSD patterns were indexed with HKL Technology's CHANNEL $5^{\circledR i}$ software. The misorientation between grains is described using the angle and axis for the smallest possible rotation that can be applied to one grain to achieve lattice coincidence with the other. Misorientation angle and axis were calculated from crystal orientation using the CHANNEL $5^{\text {(iil }}$ software according to the method of Randle and Engler (2000). The distribution of misorientation angles between adjacent grains (i.e. correlated misorientations) is compared with the theoretical distribution of

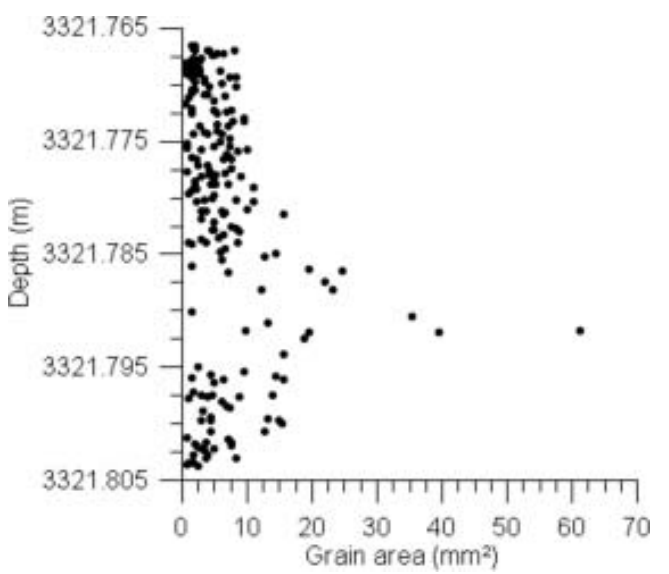

Fig. 4. Variation in grain area with depth for vertical thin section from 3321.765 to $3321.805 \mathrm{~m}$. The $x$ axis is grain area, which is determined by pixel counting and plotted at the depth of the center of mass of each grain.

misorientation angles between randomly oriented hexagonal grains and the distribution of misorientation angles between each grain pairing in the sample (uncorrelated misorientations). An uncorrelated distribution that differs from the theoretical random indicates a preferred orientation throughout the material (fabric). A non-random distribution of correlated misorientations suggests a special relationship between some adjacent grains such as that found with twinning.

\section{RESULTS}

\subsection{Texture}

Thin sections and average grain area for representative shallow specimens and all specimens from a depth of over $2700 \mathrm{~m}$ are shown in Figure 2. Texture data for all sections are shown in Table 1. Grain size (area) generally increases with age, with a few notable exceptions, as shown in Figure 3. We calculated the age of the core at each depth using the data presented by Salamatin and others (2004) and linear interpolation between ages of adjacent depths (personal communication from V. Lipenkov, 2005). The ages determined for the samples from the $\mathrm{A}_{4}$ zone (494 506 years BP at $3399.68 \mathrm{~m}$ and 519491 years BP at $3416.55 \mathrm{~m}$ ) are for plotting purposes only, as the stratigraphic disturbance in zone C, discussed
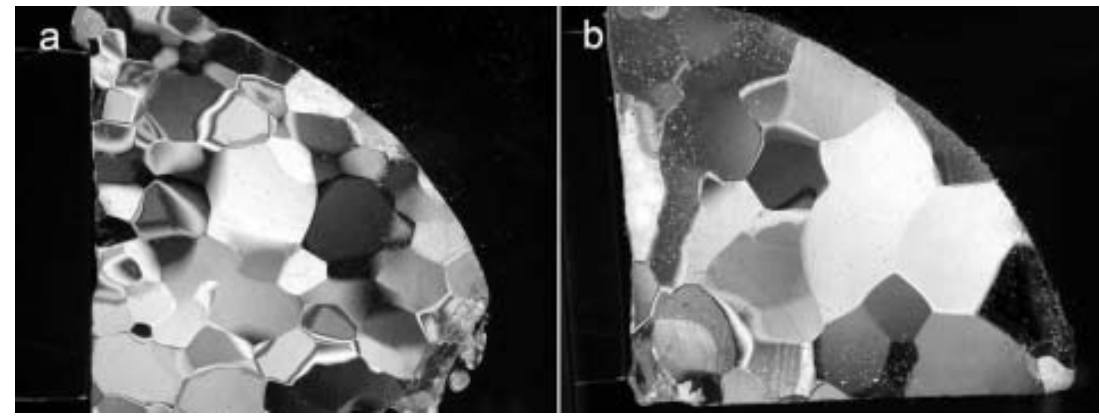

Fig. 5. Horizontal thin sections from (a) $3399 \mathrm{~m}$ and (b) $3416 \mathrm{~m}$ in the Vostok core showing no apparent difference in grain width in a horizontal direction. Sections are approximately $4 \mathrm{~cm}$ wide on the flat sides. 

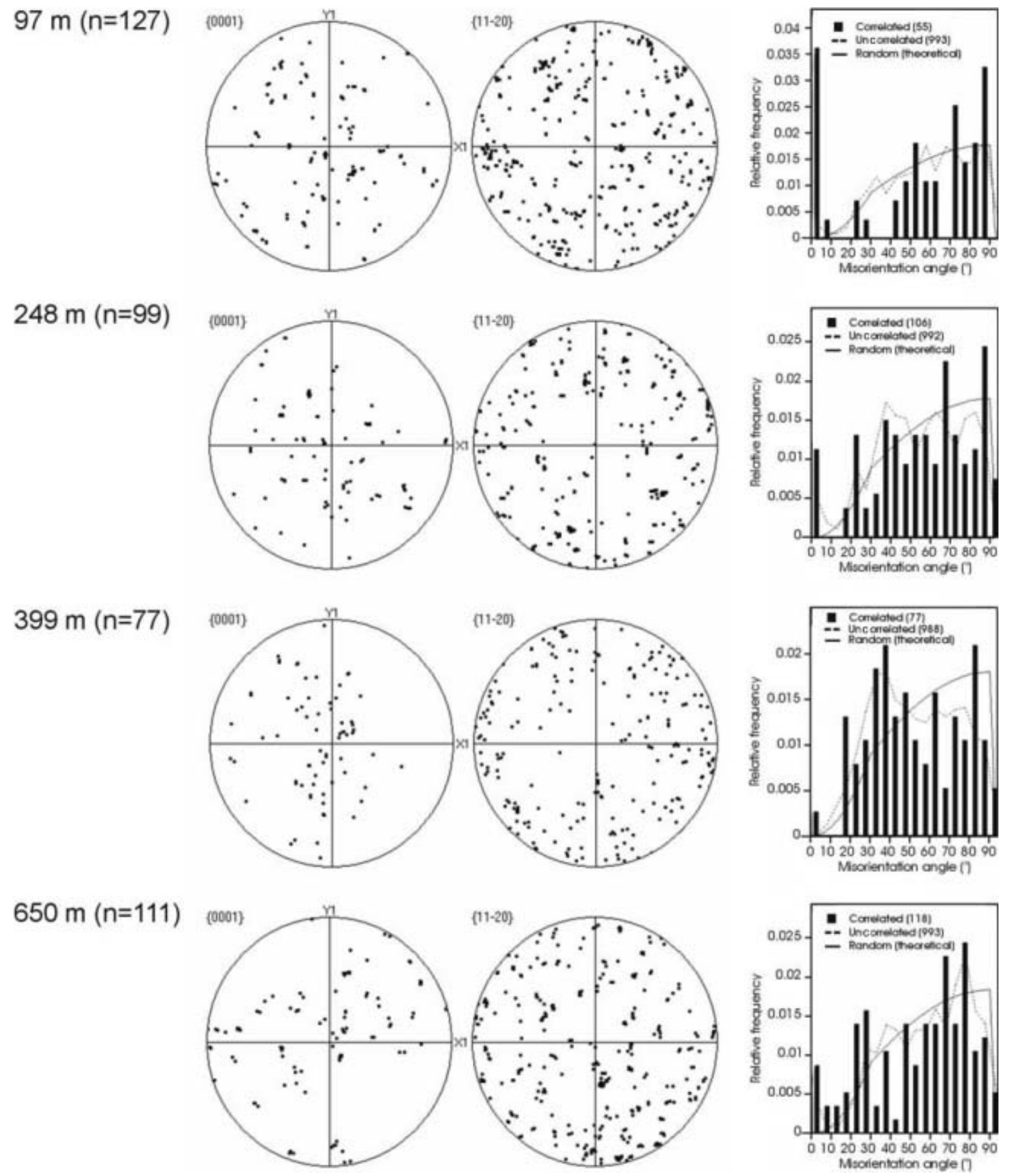

Fig. 6. Fabric diagrams and misorientation histograms for Vostok 5G sections. Plotted points are projections onto the equal-area net, of each crystal orientation intersection with the upper hemisphere. $n$ is the number of grains measured.

earlier, makes dating for these layers uncertain. A linear fit of the data from 97 to $2749 \mathrm{~m}$ and 3300,3311 and $3329 \mathrm{~m}$ is represented by:

$$
\bar{A}=-2.763+1.521 \times 10^{-4} \times t \quad\left(\mathrm{~mm}^{2}\right),
$$

where $t$ is time in years. Exceptions to the linearly increasing grain area with age are found at 2874, 3321 and $3399 \mathrm{~m}$, where the grain size is quite a bit smaller than would be expected. The $3321.765-3321.805 \mathrm{~m}$ specimen not only has an average grain size of $8.83 \mathrm{~mm}^{2}$, which is quite low, but in this case a simple average is misleading because in a thin section (Fig. 2) we see horizontal zones of significantly different grain size. Grain size is plotted as a function of depth for this thin section (representative of other sections made from this specimen) in Figure 4. Note that even the largest grains are much smaller than those that would fit Equation (1) $\left(61.167 \mathrm{~mm}^{2}\right)$. Note also that the grains in the coarser-grained layer are more equiaxed than those above or below.

Grain flattening was observed, and therefore measured, in the deeper sections and is quantified by an aspect ratio (grain width: grain height) $>1$ (see Table 1). In the 2874, 3321 and $3399 \mathrm{~m}$ specimens, not only was grain size unusually small compared with that in the other layers and with that expected from the curve represented by Equation (1), but grains were also more significantly flattened than in other layers, another sign of reduced grain growth. Aside from this vertical thinning, there were no other changes in grain shape with depth. Lipenkov and others (1989, fig. 1) show that below $100 \mathrm{~m}$, grains elongate in one 
$1201 \mathrm{~m}(\mathrm{n}=120)$

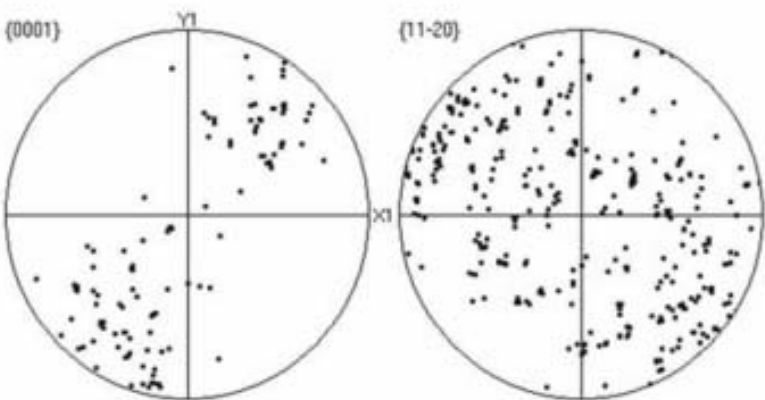

$1500 \mathrm{~m}(n=120)$

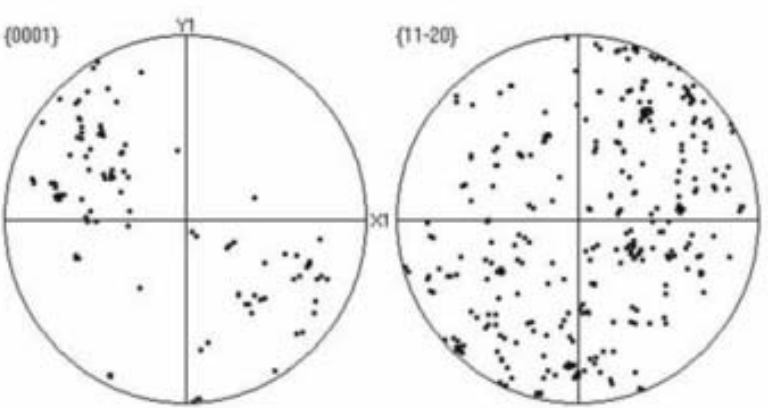

$1849 \mathrm{~m}(\mathrm{n}=77)$

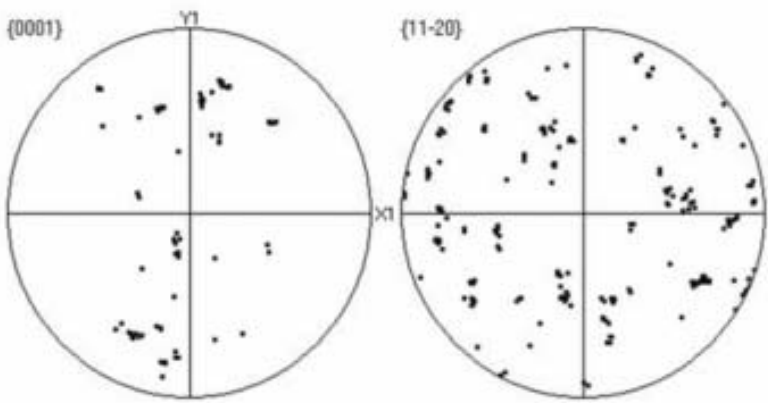

$2082 m(n=97)$

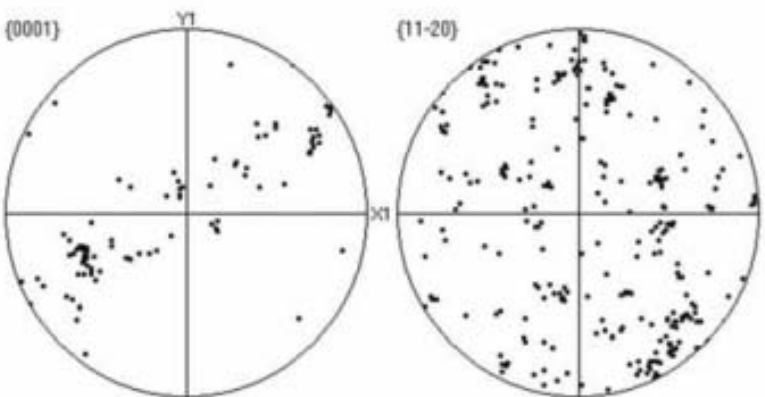

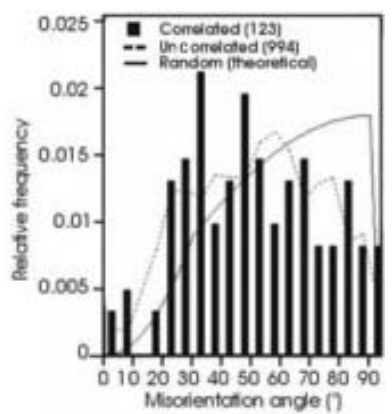
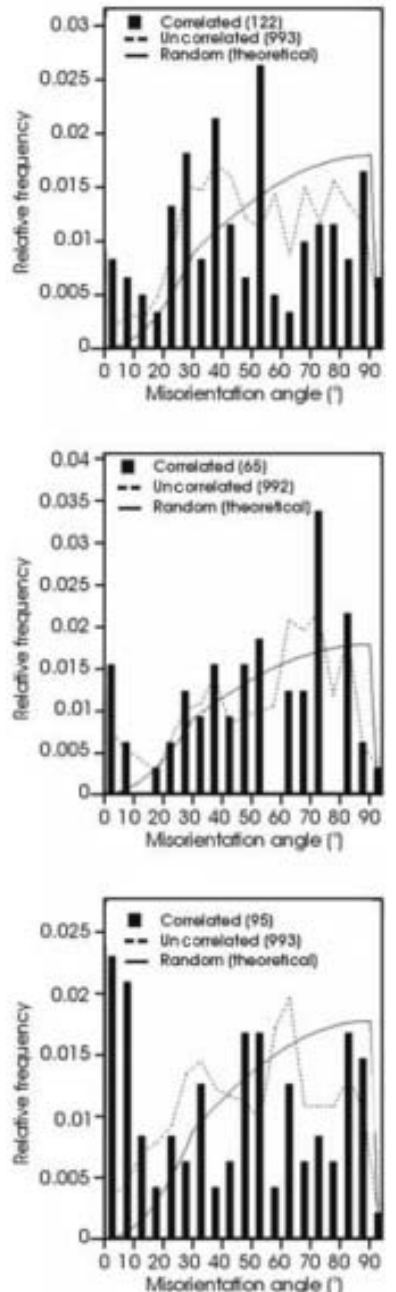

Fig. 6. (continued)

horizontal direction. Horizontal thin sections prepared from both our interglacial and glacial specimens did not reveal this (two horizontal thin sections are shown in Fig. 5).

\subsection{Fabric}

The $\{0001\}$ and $\{11 \overline{2} 0\}$ pole figures for each specimen depth are shown in Figure 6. Note that each hexagonal crystal supplies one pole on the $\{0001\}$ pole figure, but three, $60^{\circ}$ apart, on the $\{11 \overline{2} 0\}$ pole figure. In Figure 6, we see a random distribution of poles in the 97 and $248 \mathrm{~m}$ specimens. The pronounced vertical girdle is first noted at $1201 \mathrm{~m}$, and then in eight out of the remaining eleven specimens, where it strengthens with depth. A singlemaximum fabric is observed in the deeper layers that are associated with the glacial periods, as reported by Lipenkov and others (1989). The deeper layers possessing a single maximum (2874, 3321 and $3399 \mathrm{~m}$ ) correspond with those with abnormally small grain sizes and greater flattening. In the $\{0001\}$ pole figures from depths of $1500 \mathrm{~m}$ and greater, there are some clusters of poles. These indicate grains having similar $c$ axis orientations, and suggest a preferred orientation or fabric. However, the clusters alone do not tell us anything about the relative location of these grains in the specimens. For those depths also characterized by many low-angle $\left(1-10^{\circ}\right)$ misorientations between correlated (adjacent) grain pairs, these clusters may be indicative of polygonization. This possibility is addressed in section 4, and a more in-depth examination of the theory behind it can be found in Obbard and others (2006b). 

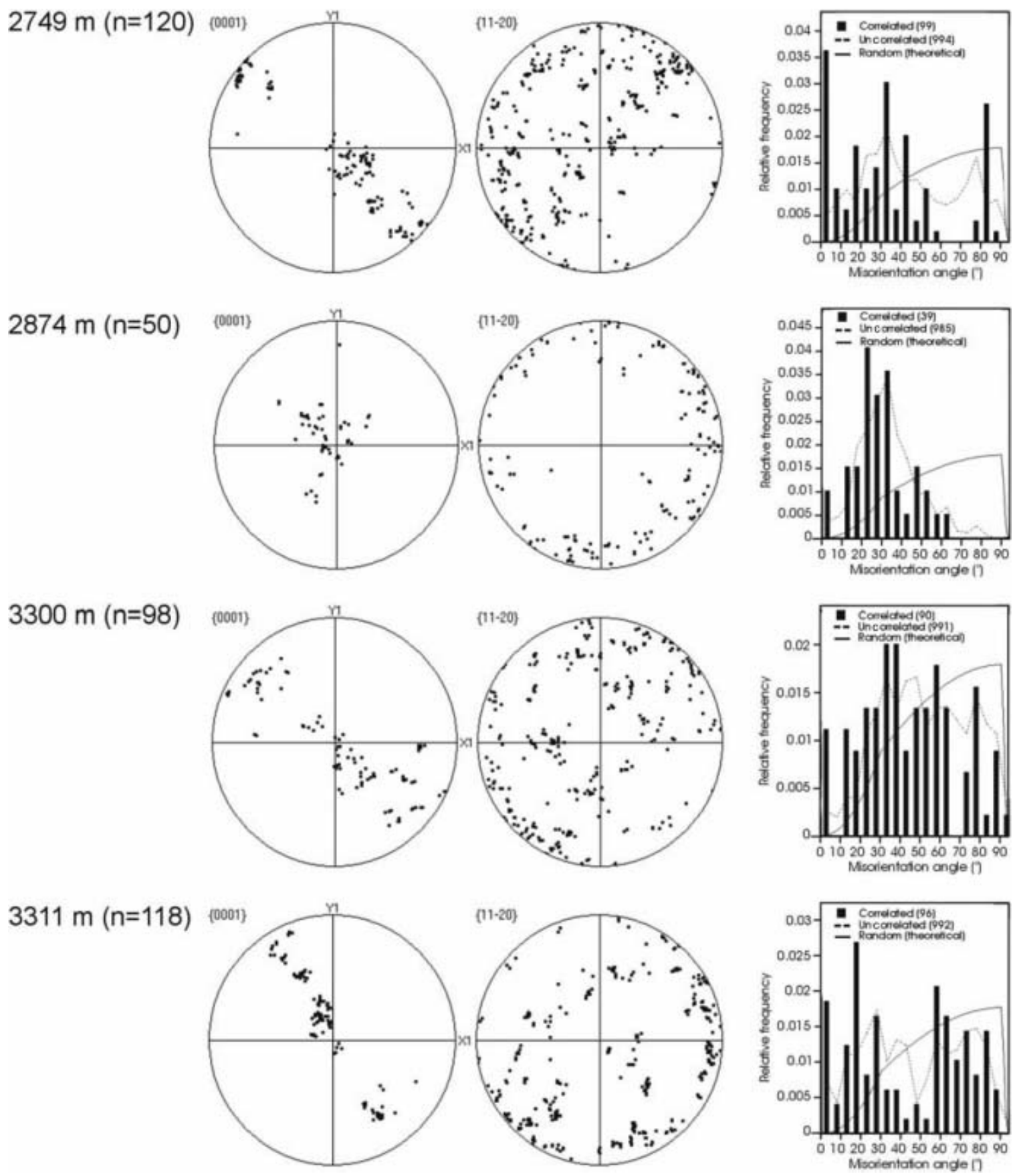

Fig. 6. (continued)

The distribution of correlated misorientation angles for each depth is also shown in Figure 6, along with the random (theoretical) distribution curve (solid line) and the distribution of uncorrelated misorientation angles (dashed line). The calculated misorientations are binned into $5^{\circ}$ groups, so the vertical axis must be multiplied by five for the groups to sum to unity. At 97 and $248 \mathrm{~m}$, where the fabric is randomly oriented, the misorientation angle distribution, both correlated and uncorrelated, is also reasonably random. The vertical-girdle fabric seen in pole figures for many of the deeper specimens is manifested in the non-random nature of the uncorrelated misorientation distribution. The correlated misorientations for these specimens are more heavily weighted toward the low $\left(0-10^{\circ}\right)$ angles than the overall (uncorrelated) misorientation (fabric). In the specimens with a strong singlemaximum fabric, both the uncorrelated and correlated misorientations are predominantly $<40^{\circ}$. This is additional evidence of the strong fabric in these specimens, and of the lack of special relationships between adjacent grains.

\subsection{Impurity content}

Impurity content is shown in Table 2. Soluble impurities are those soluble in the $25^{\circ} \mathrm{C}$ meltwater and hence measured with ion chromatography. Dust levels were measured with laser light scattering through the solid, and thus would include the soluble portion, if any, of particulates. Hence we call dust (and ash) particulates rather than insoluble impurities.

\subsubsection{Soluble impurities}

Variations in concentrations of specific ions over the two or three runs can be seen and may be due to the location in the 

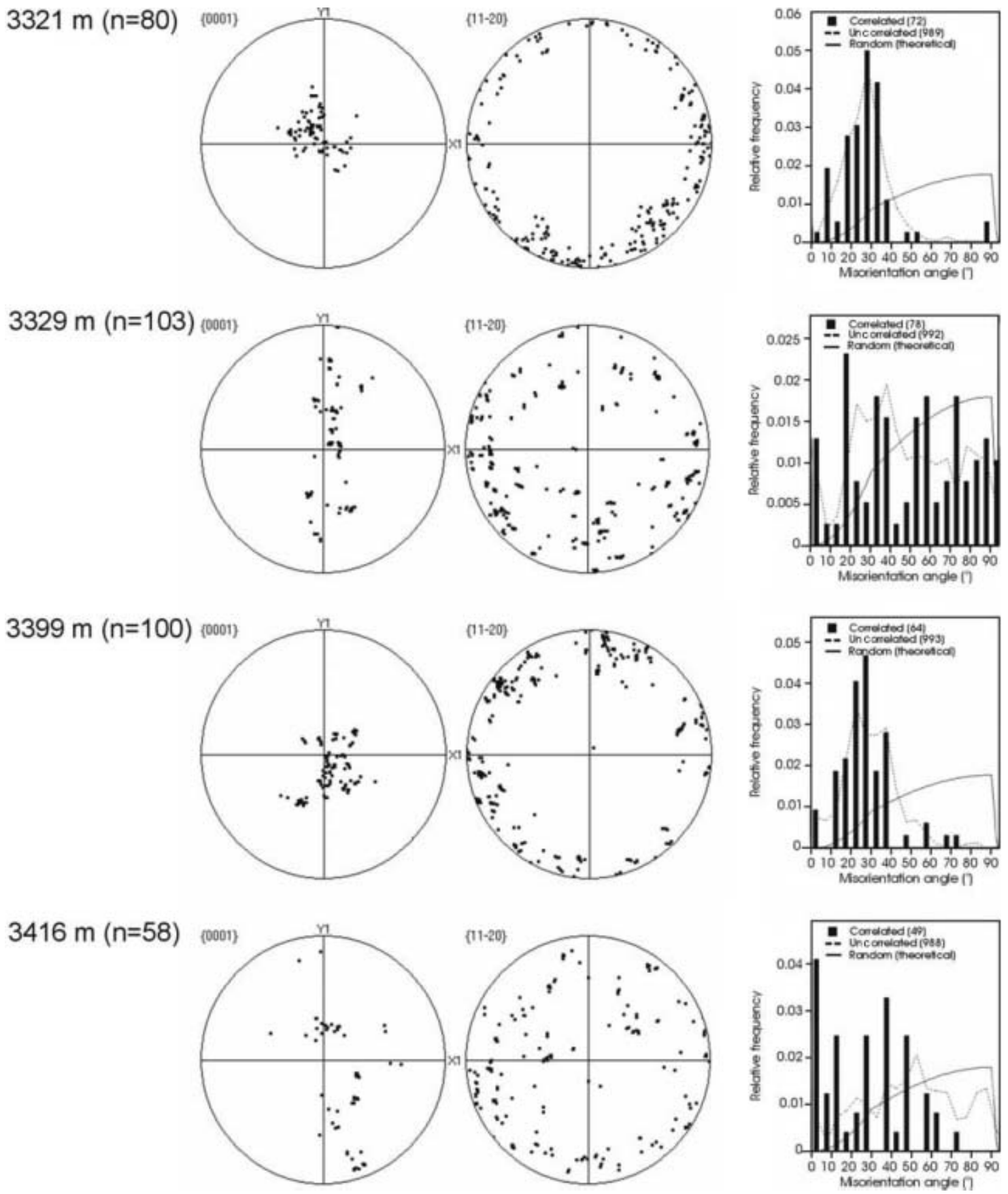

Fig. 6. (continued)

specimen from which the sample was cut. Initial samples were cut horizontally from the bottom of the specimens. Thus, the first anion concentration value shown for each depth is not necessarily representative of the whole $3-4 \mathrm{~cm}$ thick specimen. Second and third anion samples and all cation samples were cut vertically from the specimens and so tend to yield average concentrations over a depth of 3-4 cm. To assess the repeatability of the test set-up, back-toback cation runs from the same bottle of melt were carried out for $3311 \mathrm{~m}$ and were within $2 \mathrm{ppb}$ for each cation measured (hence only one of these values is shown in Table 2). However, the first two sets of anion analysis of the $3311 \mathrm{~m}$ specimen shown in Table 2 were run on successive days from different bottles of melt (which came from different pieces of the specimen) and are not within the anion IDL, e.g. $\mathrm{Cl}^{-}$concentration was $135 \mathrm{ppb}$ on the first day and $220 \mathrm{ppb}$ on the second day compared with an IDL of $20 \mathrm{ppb}$. Thus, samples made from pieces cut vertically from $3-4 \mathrm{~cm}$ of core are unlikely to yield the same results each time or to be representative of smaller layers within the specimen, such as those found at $3321 \mathrm{~m}$. Results from continuous ion chromatography would provide more precise ion concentration data, but are not available for part of the core examined in detail herein (Legrand and others, 1988).

\subsubsection{Particulates}

The dust concentration data included in Table 2 were compiled from Petit and others (1999) and Simões and others (2002) by V. Lipenkov (personal communication, 2004) and include values from both the $3 G$ and $5 G$ cores at Vostok station, as indicated. These data were not collected continuously for the core and are available only at intervals 
Table 2. Impurity concentration in mass ppb

\begin{tabular}{|c|c|c|c|c|c|c|c|c|c|}
\hline \multirow{3}{*}{$\begin{array}{l}\text { Depth } \\
\text { m }\end{array}$} & \multirow{3}{*}{$\begin{array}{c}\text { Age } \\
\text { years BP }\end{array}$} & \multirow{3}{*}{$\begin{array}{l}\mathrm{Cl}^{-} \\
\mathrm{ppb}\end{array}$} & \multirow{3}{*}{$\begin{array}{c}\mathrm{NO}_{3}^{-} \\
\mathrm{ppb}\end{array}$} & \multirow{3}{*}{$\begin{array}{c}\mathrm{SO}_{4}^{2-} \\
\mathrm{ppb}\end{array}$} & \multicolumn{2}{|c|}{ Concentration } & \multirow{3}{*}{$\begin{array}{l}\mathrm{Ca}^{2+} \\
\mathrm{ppb}\end{array}$} & \multirow{3}{*}{$\begin{array}{c}\mathrm{Mg}^{2+} \\
\mathrm{ppb}\end{array}$} & \multirow{3}{*}{$\begin{array}{l}\text { Dust } \\
\mathrm{ppb}\end{array}$} \\
\hline & & & & & $\mathrm{Na}^{+}$ & $\mathrm{K}^{+}$ & & & \\
\hline & & & & & $\mathrm{ppb}$ & $\mathrm{ppb}$ & & & \\
\hline 97 & 3450 & & & & & & & & \\
\hline $248.15-248.19$ & 10084 & 85 & 146 & 240 & & & & & $30(249)^{1}$ \\
\hline \multirow[t]{3}{*}{399} & 20160 & 576 & 455 & 420 & 2687 & 381 & 540 & 61 & $973(399)^{1}$ \\
\hline & & 1142 & 709 & 509 & & & & & \\
\hline & & 1134 & 708 & 511 & & & & & \\
\hline \multirow[t]{3}{*}{$650.325-650.395$} & 39565 & 158 & 54 & 211 & 293 & 283 & 137 & 31 & $210(650)^{1}$ \\
\hline & & 151 & 49 & 228 & & & & & \\
\hline & & 154 & 44 & 232 & & & & & \\
\hline \multirow[t]{2}{*}{1201} & 84322 & 110 & 698 & 175 & & & & & $78(1199)^{1}$ \\
\hline & & 57 & 175 & 155 & & & & & \\
\hline \multirow[t]{3}{*}{1500} & 108372 & 82 & 273 & 162 & & & & & $85(1500)^{1}$ \\
\hline & & 85 & 200 & 172 & & & & & \\
\hline & & 80 & 195 & 178 & & & & & \\
\hline 1849.875-1849.915 & 127978 & 10440 & 19049 & 139140 & 119 & 167 & 139 & 10 & $20(1850)^{1}$ \\
\hline $2082.13-2082.17$ & 149231 & 307 & 2318 & 312 & & & & & $318(2081)^{2}$ \\
\hline \multirow[t]{2}{*}{2749} & 239952 & 923 & 5193 & 242 & & & & & $33(2748)^{3}$ \\
\hline & & 403 & 1791 & 147 & & & & & \\
\hline \multirow[t]{2}{*}{ 2874.49-2874.53 } & 269226 & 559 & 507 & 434 & 162 & 50 & 117 & 34 & $554(2875)^{3}$ \\
\hline & & 225 & 211 & 242 & & & & & \\
\hline \multirow[t]{3}{*}{$3300.68-3300.72$} & 410402 & 255 & 395 & 171 & & & & & $15(3303)^{3}$ \\
\hline & & 863 & 214 & 157 & & & & & \\
\hline & & 168 & 242 & 150 & & & & & \\
\hline \multirow{3}{*}{$3311.45-3311.49$} & 414851 & 135 & 546 & 143 & 58 & 80 & 73 & 9 & $22(3315)^{3}$ \\
\hline & & 220 & 1399 & 167 & & & & & \\
\hline & & 121 & 253 & 219 & & & & & \\
\hline \multirow[t]{2}{*}{$3321.765-3321.805$} & 420314 & 278 & 626 & 256 & 288 & 203 & 409 & 70 & $996(3321)^{3}$ \\
\hline & & 258 & 334 & 391 & & & & & \\
\hline \multirow{2}{*}{$3329.46-3329.50$} & 424589 & 488 & 1145 & 159 & 94 & 160 & 93 & 12 & $30(3330)^{3}$ \\
\hline & & 202 & 946 & 167 & & & & & \\
\hline $3399.66-3399.70$ & Unknown & 219 & 110 & 201 & 366 & 176 & 254 & 32 & $382(3401)^{3}$ \\
\hline $3416.55-3416.56$ & Unknown & 636 & 254 & 253 & & & & & $58(3416)^{3}$ \\
\hline
\end{tabular}

Notes: Age is calculated as described in the text. Multiple values indicate separate tests on samples from that depth. Initial anion tests were conducted on the bottom $10 \mathrm{~mm}$ of the sample. All other tests are averages over the $3-4 \mathrm{~cm}$ sample thickness. Also included are insoluble particle (dust) concentration data measured in meltwater from the nearest available tested depth. These data are from three different cores: ${ }^{1} 3 \mathrm{G},{ }^{2} 3 \mathrm{G} 1,{ }^{3} 5 \mathrm{G}$ (Lipenkov, 2004$)$.

of $1 \mathrm{~m}$ or more, hence the value for the closest available depth is listed, usually given only to the nearest meter.

Visual inspection revealed dark horizontal bands in the 2874 and $3321 \mathrm{~m}$ specimens. These and similar bands, typically a few millimeters wide, were visible in the $1 \mathrm{~m}$ core sections at NICL from which these specimens were cut. One such band was located at 2874.526-2874.530 m, and is therefore included in the initial ion-chromatography test for the $2874 \mathrm{~m}$ specimen. (It also coincided with the especially fine-grained region at the bottom of the $2874 \mathrm{~m}$ thin section in Figure 2.) Annual fluctuations in dust content of snow have been observed and in fact are used for visual stratigraphy. However, the bands seen in these sections of the core are too far apart to correspond with a regular annual pattern and are probably volcanic in origin, like the ash bands noted at $3311 \mathrm{~m}$ by Petit and others (1999). As an example, in the $3321 \mathrm{~m}$ specimen, the dark bands are approximately $15 \mathrm{~mm}$ apart (Fig. 7a), the equivalent here of approximately 10 years. In Figure $7 \mathrm{~b}$, the thin section for this specimen is shown so that it corresponds in depth with the photograph in Figure 7a. The position of the dark bands in Figure $7 \mathrm{a}$ is roughly correlated with that of the fine-grained layers in the middle and bottom of the specimen in Figure $7 \mathrm{~b}$, but the width of the dark bands does not match the width of the finegrained layers.

\subsection{SEM/EDS results}

Small white spots $(1-5 \mu \mathrm{m})$ are typically seen in the lattice, where their pattern gives an indication of grain orientation (Obbard and others, 2006a). Those that drift or disperse when subjected to a focused electron beam are called white spots, rather than particulates, in the following discussion. The oxygen peak dominates the EDS spectra of white spots, but $\mathrm{Cl}, \mathrm{Na}$ and occasionally other elements are detected as well. During some periods of SEM use, carbon is found in the white spots. During one of these periods, ice frozen in a clean container from deionized water yielded the same distribution of small white spots containing carbon, in an examination of both freshly grown surfaces and those prepared by cutting and shaving the ice using clean tools in the standard method. The authors concluded that the carbon is a contaminant that is sometimes present in the SEM, perhaps due to backstreaming or operation of the diffusion pump at high temperatures. When the small carbon peaks are present, they are found in all ice samples examined during that period. Therefore, carbon peaks much smaller than the 


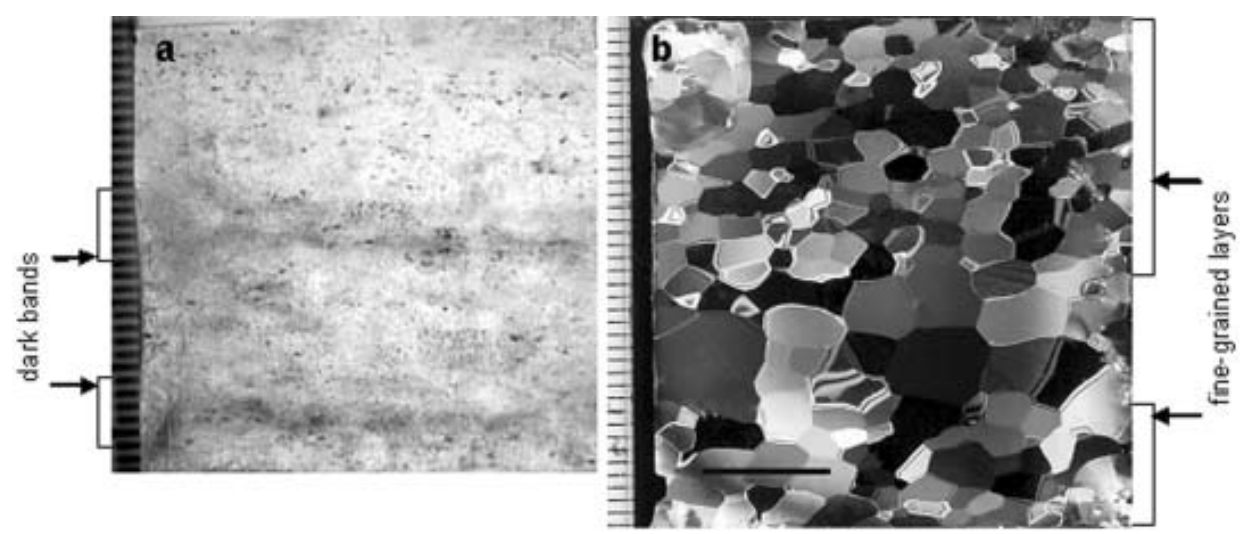

Fig. 7. Vostok $3321 \mathrm{~m}$ specimen images aligned in depth. (a) The 3321.765-3321.800 m specimen photographed on a light table before thin sectioning. (The bottom $\sim 5 \mathrm{~mm}$ was used for ion chromatography.) (b) The 3321.765-3321.805 $\mathrm{m}$ thin section photographed between crossed polarizers.

oxygen peak are disregarded when found in small drifting white spots in all samples tested within the same period.

In some cases, larger white spots on the order of 5-10 $\mu \mathrm{m}$ are seen on the grain boundaries. Samples from the anomalously fine-grained layers from 2874.49-2874.53, $3399.66-3399.70$ and 3321.765-3321.805 $\mathrm{m}$ had an unusual concentration of impurities on the grain boundaries that were primarily composed of $\mathrm{Ca}, \mathrm{Cl}$ and $\mathrm{K}$. These elements are not uncommon, but this is the first time Ca has been found in concentrated points on grain boundaries.

Figure 8 shows two triple junctions and their associated grain boundaries in a sample from $2874 \mathrm{~m}$. These grain boundaries, like others in samples from this depth, contained a number of small white spots $(1-5 \mu \mathrm{m})$, and EDS revealed that these typically contained $\mathrm{Ca}$ and $\mathrm{Cl}$, and often $\mathrm{K}$ and $\mathrm{S}$ as well. Particulates in the lattice at this depth were found to contain the usual $\mathrm{Si}$ and $\mathrm{Al}$, and sometimes $\mathrm{Ca}, \mathrm{K}$ and $\mathrm{Fe}$.

In samples from $3399 \mathrm{~m}$, the 5-10 $\mu \mathrm{m}$ grain-boundary white spots were of two types. Some, which in one instance coalesced into a line in a grain boundary, had EDS spectra revealing primarily $\mathrm{Cl}$ and $\mathrm{Na}$, with small peaks for other elements, including Ca (Fig. 9b). Others contained Ca and S (Fig. 9b). Smaller white spots $(1-5 \mu \mathrm{m})$ in the lattice contained $\mathrm{Si}, \mathrm{Al}, \mathrm{K}$ and $\mathrm{S}$ (Fig. 9b).

The 3321.765-3321.805 $\mathrm{m}$ specimen was unique because it contained three distinct layers. The top $20 \mathrm{~mm}$ and bottom $3 \mathrm{~mm}$ are especially fine-grained, while the middle $17 \mathrm{~cm}$ (3321.785-3321.802 m) is composed of relatively larger grains, but even these are smaller than would be expected for this depth. Hence this middle layer is referred to as the 'larger-grained layer'. The top and bottom finegrained layers are termed fine-grained layers 1 and 2, respectively. While all three layers shared the single-maximum fabric and misorientation angle distribution shown in Figure 6 (the orientations of approximately 50 grains in each layer were measured independently), they were different in the type and location of their impurities.

Fine-grained layer 1 (3321.765-3321.785 m) had 5$10 \mu \mathrm{m}$ grain-boundary white spots containing $\mathrm{Si}, \mathrm{Al}$ and $\mathrm{Mg}$ (Fig. 10a). Some white spots also contained $\mathrm{S}$ and $\mathrm{Cl}$ (Fig. 10b), while others contained $\mathrm{K}$ and $\mathrm{Ca}$ (Fig. 10c). This layer also had large $5-10 \mu \mathrm{m}$ white spots in the lattice, containing $\mathrm{Si}, \mathrm{Al}, \mathrm{K}$ and $\mathrm{Ca}$.

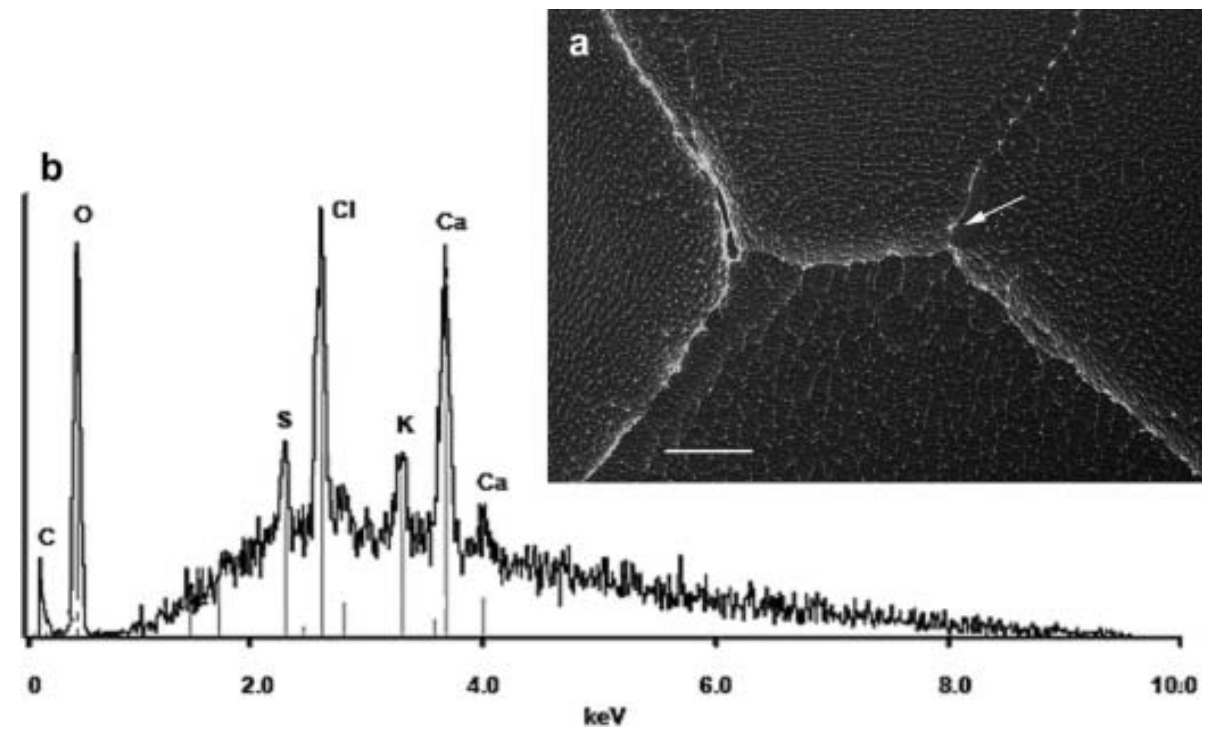

Fig. 8. Vostok $2874 \mathrm{~m}$ triple junctions and grain boundaries. (a) SEM image showing an abundance of white spots in grain boundaries (scale bar is $100 \mu \mathrm{m})$. (b) EDS spectra from a representative spot (indicated). 

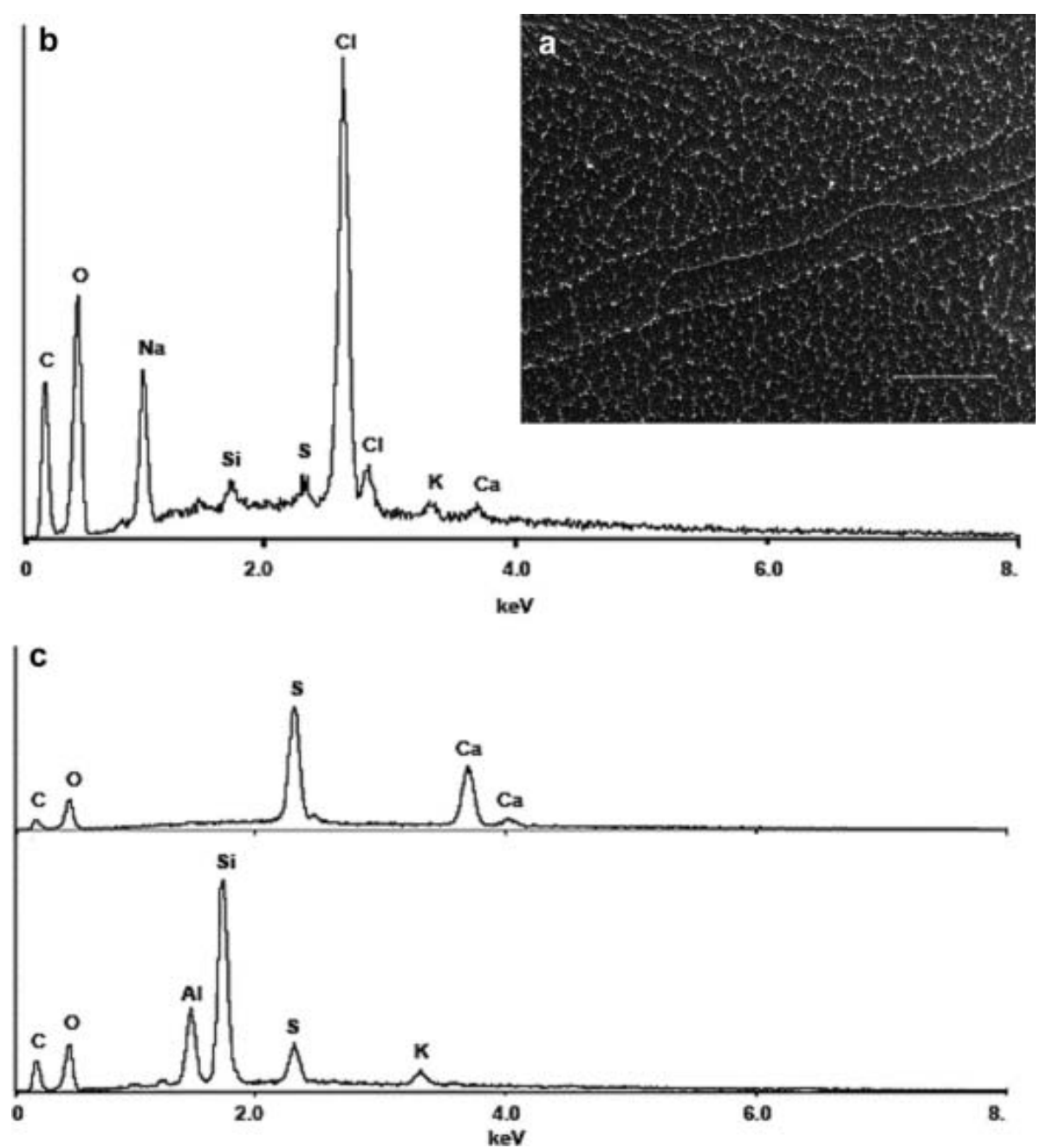

Fig. 9. Vostok $3399 \mathrm{~m}$ (a) grain boundary with white spots and thread (scale bar is $100 \mu \mathrm{m}$ ), (b) EDS spectra of small grain-boundary white spots and thread, and (c) EDS spectra of larger white spots on grain boundary (top) and in lattice (bottom).

Fine-grained layer 2 (3321.802-3321.805 m) had 5$10 \mu \mathrm{m}$ white spots on the grain boundaries and in the lattice (Fig. 11a), all of which contained Ca, Cl, K and S (Fig. 11b). This layer also has very large particulates in the lattice, which contained $\mathrm{Si}, \mathrm{Al}, \mathrm{Cl}, \mathrm{Ca}$ and $\mathrm{C}$.

In the larger-grained layer in the middle (3321.785$3321.802 \mathrm{~m}$ ) the white spots on the grain boundaries were smaller $(1-5 \mu \mathrm{m})$ (Fig. 12a) and contained Cl, K, Si, Na and S (Fig. 12b). No Ca or Al was found in white spots in the lattice or grain boundaries of this larger-grained layer.

Larger impurities, typically $10-50 \mu \mathrm{m}$, observed in the SEM, which rarely move during analysis and which have a defined shape, are termed particulates. Many samples of the Vostok core had particulates in the lattice which most often contained $\mathrm{Si}$ and $\mathrm{Al}$, often $\mathrm{K}, \mathrm{Na}$ and $\mathrm{Ca}$, and sometimes $\mathrm{Cl}$, $\mathrm{Mg}, \mathrm{Fe}, \mathrm{S}$ and even Ti. When present, these particulates are generally evenly distributed across the sample surface, and their location is not correlated with grain boundaries. Examples are shown in Figure 13. Details are lost with magnification above $\times 3000$ when examining uncoated ice, so, to examine the particles in more detail, meltwater was filtered through a $0.1 \mu \mathrm{m}$ cellulose filter and the remaining particles examined in the SEM at $20 \mathrm{kV}$. A typical insoluble particle obtained this way is shown with its spectra in Figure 14. A thin layer of gold was sputtered onto some samples to eliminate the effects of charging on the image.
A specimen prepared this way is shown, with its associated spectra, in Figure 14c and d.

\section{INTERPRETATION AND DISCUSSION}

\subsection{Texture}

The crystal or grain size (area) in many polar ice cores initially increases linearly with the age of the ice (Gow and Williamson, 1976; Duval and Lorius, 1980) according to the grain-growth equation (Beck, 1954):

$$
\bar{A}=\bar{A}_{0}+K t,
$$

where $\bar{A}$ is the mean grain area at time $t$ and $\bar{A}_{0}$ is the average initial grain cross-sectional area at pore close-off. The growth rate, $K$, is temperature-dependent and obeys an Arrhenius-type relationship as shown in Equation (3) (Gow, 1969; Duval and Lorius, 1980; Alley and Woods, 1996):

$$
K=K_{0} \mathrm{e}^{-Q / R T}
$$

where $Q$ is the activation energy of the growth process, which Paterson (1994) has estimated at $42.4 \mathrm{~kJ} \mathrm{~mol}^{-1}$ based on crystal growth in firn, $K_{0}$ is a constant, and $R$ is the gas constant. $K$ is related not only to the in situ temperature, $T$, but also to the intrinsic properties of polycrystalline ice (grain size, shape and orientation distribution) and to the 


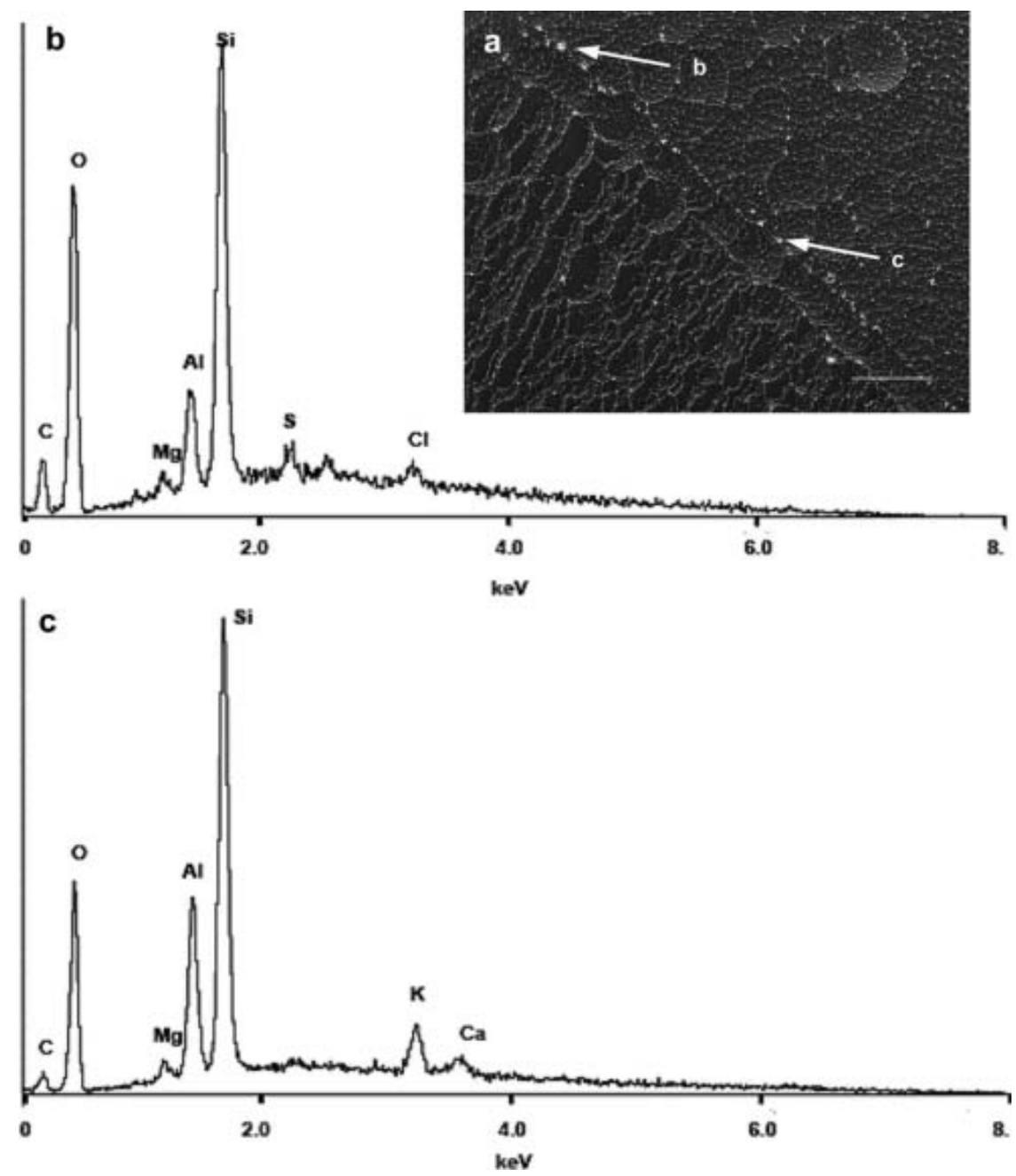

Fig. 10. Vostok $3321 \mathrm{~m}$ fine-grained layer $1(3321.765-3321.785 \mathrm{~m})$ (a) white spots on grain boundaries and in the lattice (scale bar is $100 \mu \mathrm{m})$, and (b, c) EDS spectra for grain-boundary spots.

presence of dissolved impurities, particles and bubbles in the ice (Alley and others, 1986a, b).

The growth rate, $K$, in Equation (1) can be compared to other published values, such as the values listed in Paterson (1994) for ice crystals in polar firn. For Vostok $\left(-57^{\circ} \mathrm{C}\right)$, the author gives $8 \times 10^{-4} \mathrm{~mm}^{2} \mathrm{a}^{-1}$, from Barkov and Lipenkov (1984). However, crystal growth rates are strongly temperature-dependent, and the growth rates in Paterson's table (Paterson, 1994, table 2.5) are for polar firn. Gow (1969) notes that crystal growth is especially rapid in the top $10 \mathrm{~m}$ of the firn due to the effect of a sustained temperature gradient in a slowly accumulating snowpack, and potentially also because, in the firn, crystals grow at the expense of grains. Below $10 \mathrm{~m}$, where temperature becomes more constant, crystal growth is slower. Gow's (1969) extrapolation of his data for crystal growth in polar firn showed that rates in Antarctica could be expected to vary by at least two orders of magnitude depending on temperature, from a low of $3 \times 10^{-4} \mathrm{~mm}^{2} \mathrm{a}^{-1}$ at $-60^{\circ} \mathrm{C}$ to a high of $300 \times 10^{-4} \mathrm{~mm}^{2} \mathrm{a}^{-1}$ at $-15^{\circ} \mathrm{C}$.

In more recent work, Lipenkov and others (1999) made an attempt to compile and uniformly scale the data from different sources in which grain size had been measured using different methods. Their data came from 18 ice cores from Antarctica and Greenland and included the data that led to their earlier value for growth rate (Barkov and
Lipenkov, 1984). This time, they assumed a single grain size and shape (octahedral) in each sample, in order to derive a simple relationship between grain size and bubble geometry at pore close-off, and scaled the average crosssectional areas uniformly to correspond with this. After such scaling, the grain growth at Vostok was about $3 \times$ $10^{-4} \mathrm{~mm}^{2} \mathrm{a}^{-1}$ (personal communication from V. Lipenkov, 2006).

Taken in this context, our grain growth rate of $1.52 \times$ $10^{-4} \mathrm{~mm}^{2} \mathrm{a}^{-1}$ for the limited data we had in the interval $97-3329 \mathrm{~m}$ is not unreasonable, particularly given the impact of different grain-size measurement techniques. Finally, we note that crystal growth is also affected by stress and that caution must be exercised when comparing actual growth in regions of deformation and non-random fabrics to the normal crystal growth embodied in Equation (2). The growth rate, $K$, discussed above was calculated using grainsize data from depths associated with varied climatic conditions (temperature and impurity load) and those at which polygonization may be taking place (this matter is addressed later).

The constant $A_{O}$ in Equation (2) is the mean grain area at pore close-off, while in Equation (1) it is simply the extrapolated mean cross-sectional area at time 0 . Because of the transition from snow to firn to ice in the initial $110 \mathrm{~m}$ of the core, this latter value is of no consequence. 


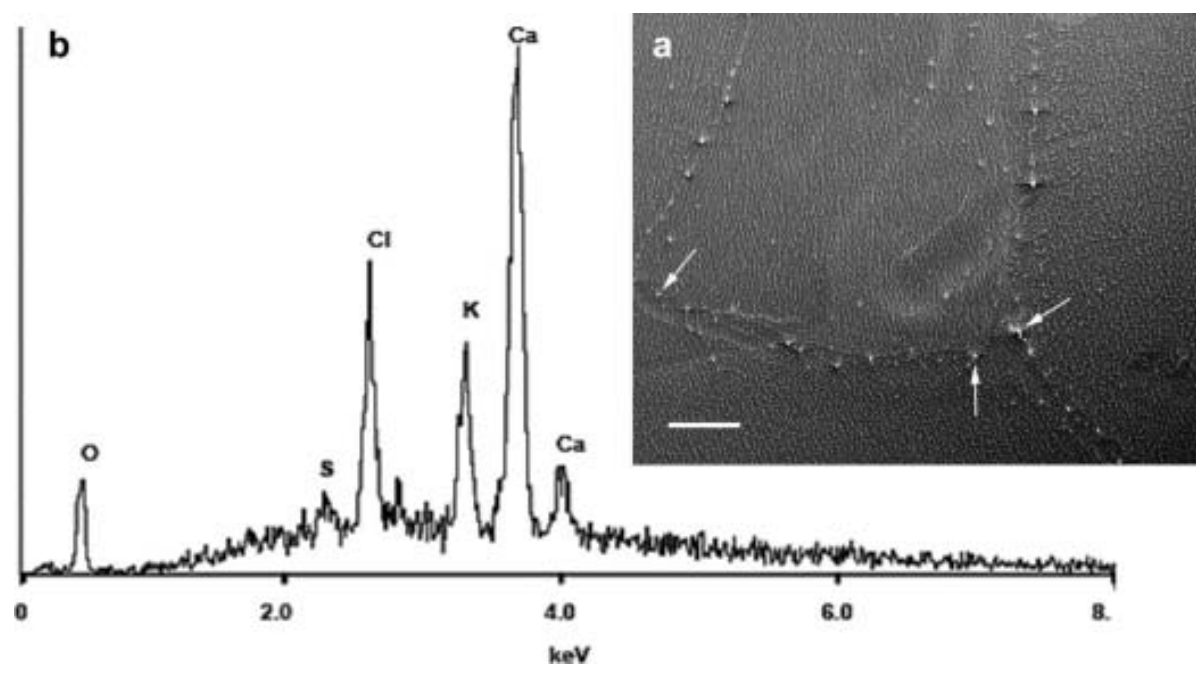

Fig. 11. Vostok $3321 \mathrm{~m}$ fine-grained layer $2(3321.802-3321.805 \mathrm{~m})$ (a) white spots on and near grain boundaries (scale bar is $100 \mu \mathrm{m})$, and (b) associated EDS spectra (representative of all points indicated).

From Equation (2), we see that the $K t$ term becomes very important for older (deeper) ice; hence differences in grain size between different strata at these depths are likely the result of variations in $K$ rather than due to differences in $A_{0}$. While $K$ depends on both the temperature and the activation energy, the temperature varies only gradually with depth, suggesting that it is the activation energy, $Q$, which must be varying between the layers that exhibit linear grain growth and adjacent ones that do not. Since grain-boundary mobility and grain growth are associated with a decrease in grainboundary energy, we seek to understand what is driving the difference in grain-boundary energy at depths where mean grain area does not fit the linear grain-growth model and the grain size is quite small and flattening more pronounced (see Table 1) compared with that in adjacent layers.

The remainder of this paper will focus on the differences between the 2874, 3321 and $3399 \mathrm{~m}$ specimens and the other specimens. Although grain size in the $3416 \mathrm{~m}$ specimen also falls below the fit line in Figure 3, there are additional factors to consider at this depth. First, there is a possibility that the impurities at this depth have multiple origins (basal as well as aeolian) and that the ice has been disturbed by interaction with the bedrock. Simões and others (2002) suggest that some of the impurities in depths between 3311 and $3538 \mathrm{~m}$, and particularly below $3450 \mathrm{~m}$ where the mode of volume size distribution shifts and particles too large for aeolian origin ( $~ 30 \mu \mathrm{m}$ in diameter) are found, may be attributable to the ice-bed interface.

Second, the temperature at $3416 \mathrm{~m}$ is high enough for migration recrystallization to take place. We do not see signs of this in crystal shape, i.e. interpenetrating crystals (Fig. 2), but have to consider that the elevated temperature at this depth may play some other role in the grain growth there (i.e. because the eutectic point for $\mathrm{NaCl}$, as one example, is $-21.2^{\circ} \mathrm{C}$ ). We also note that this depth falls between the glacial stages 14 and 16 identified by previous authors (Simões and others, 2002; Salamatin and others, 2004), and represents interglacial stage 15.

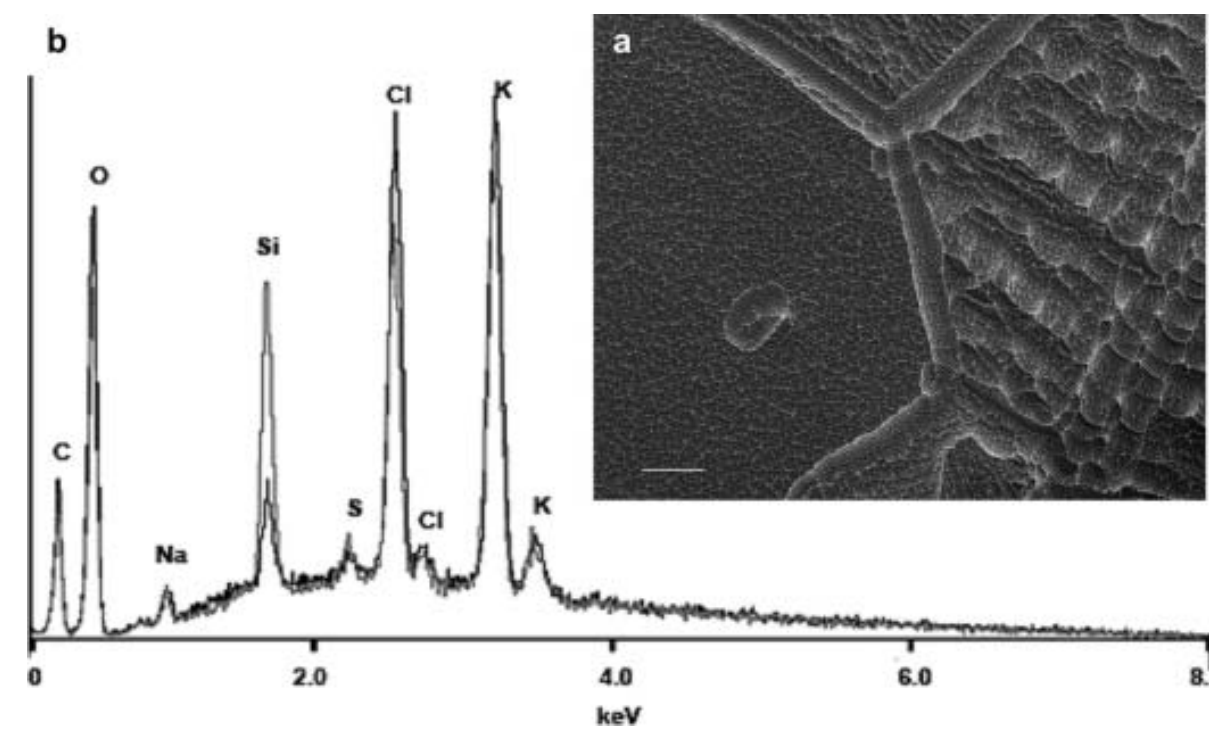

Fig. 12. Vostok $3321 \mathrm{~m}$ larger-grained layer (3321.795-3321.802 m) (a) grain boundaries and triple junctions, and (b) EDS spectra of white spots on grain boundaries. 

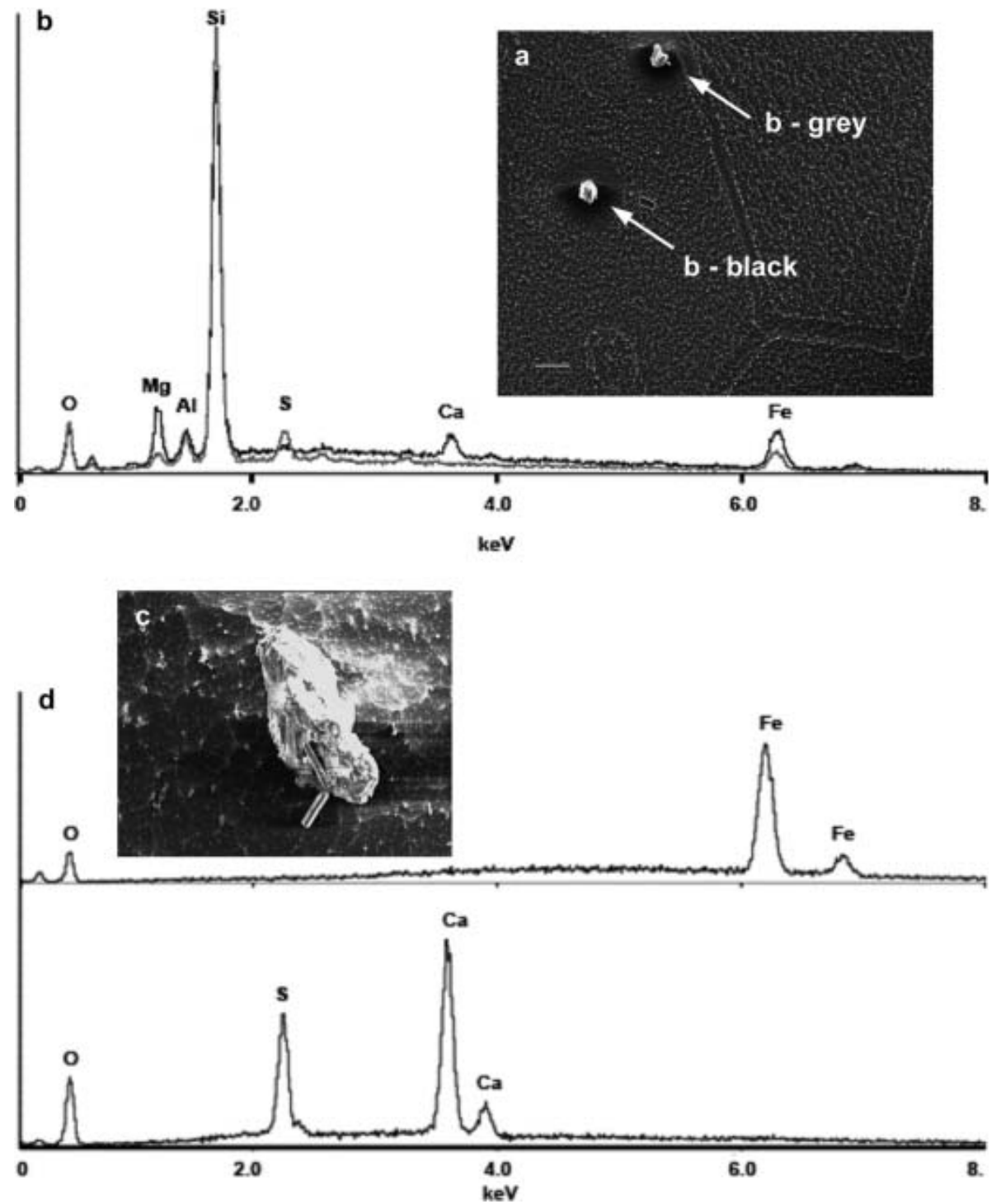

Fig. 13. Examples of particulates in lattice of $3321 \mathrm{~m}$ Vostok $5 \mathrm{G}$ core specimens. (a) Particulates in the lattice (scale bar $100 \mu \mathrm{m})$ and (b) associated EDS spectra. (c) Particle-containing rods (scale bar $10 \mu \mathrm{m}$ ) and (d) associated EDS spectra for body of particle (top) and rods (bottom).

\subsection{Fabric}

The fabric at depths of 97 and $248 \mathrm{~m}$ is random (Fig. 6). At $399 \mathrm{~m}$, the distribution of poles also appears random, but the smaller grain size (Table 1 ) at this depth than at $248 \mathrm{~m}$ and its dating (20160years BP; Table 1) from the Last Glacial Maximum (LGM) suggest that this is a glacial layer. A vertical-girdle fabric is apparent at $650 \mathrm{~m}$ and increases in strength with depth. This is consistent with Lipenkov and others (1989) who demonstrated $c$ axes 'quasi-uniformly distributed' in the upper $350 \mathrm{~m}$ of the core, trending toward clustering around the vertical plane at $454 \mathrm{~m}$ and developing into a strong vertical girdle by $2080 \mathrm{~m}$. The pole figures in Figure 6 show the fabric increasing in strength with depth all the way down to $3416 \mathrm{~m}$, with a few notable exceptions $(2874,3321$ and $3399 \mathrm{~m})$. These results for the deeper core (i.e. $3311 \mathrm{~m}$ ) are consistent with that of De La Chappelle and others (1998) for $3316 \mathrm{~m}$, as well as with that of Lipenkov and others (1989). The fabric and texture exceptions we noted at 2874, 3321 and $3399 \mathrm{~m}$, where a strong singlemaximum fabric accompanies reduced grain growth, are consistent with the layering identified in Lipenkov and
Barkov's 1998 presentation of the internal structure of the Antarctic ice sheet at Vostok station (Fig. 1). Hence we follow their naming convention and refer to the fine-grained single-maximum layers as B-type.

At the depths identified as zone C (3310-3370 m) we found two A-type layers (3311 and $3329 \mathrm{~m}$ ) separated by a B-type $(3321 \mathrm{~m})$ layer. This layering could be the result of folding, evidence of which was reported by Simões and others (2002) at $3311 \mathrm{~m}$, but the dark bands we observed in the $3321 \mathrm{~m}$ specimen are not tilted and there is nothing else to suggest that folding is the cause of the A-B-A layering here. What Lipenkov and Barkov characterize as zone $C$ could simply be $A_{3}$ (extending to at least $3311 \mathrm{~m}$ ), $B_{3}$ (extending from $A_{3}$ to at least $3321 \mathrm{~m}$ ) and $A_{4}$ (beginning by $3329 \mathrm{~m})$.

\subsection{Comparison with fine-grained layers in other deep cores}

The variation in crystal size, specifically the sudden decrease in size at certain depths, can be compared with similar phenomena noted in the Greenland Icecore Project 

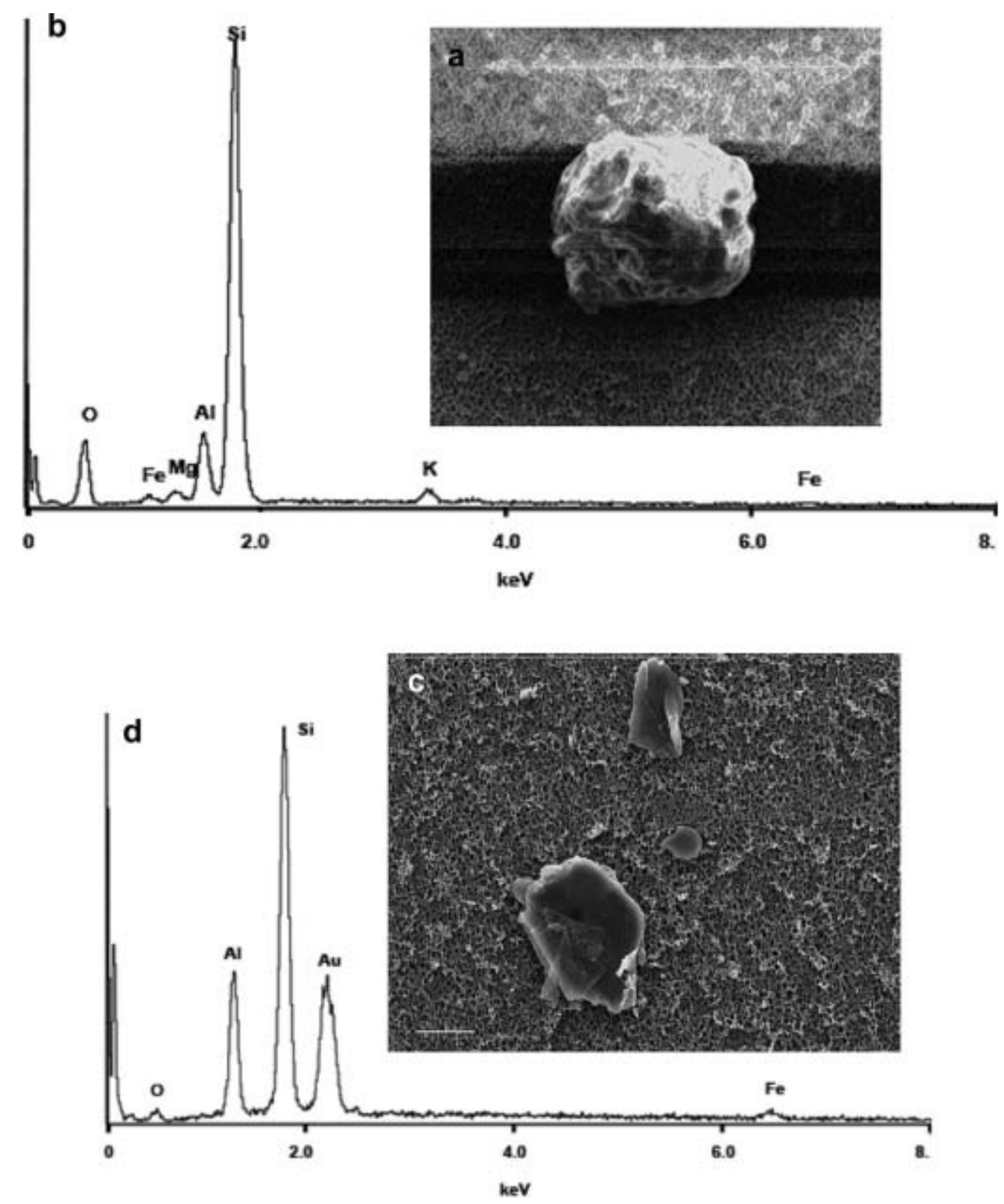

Fig. 14. Vostok 5G $2874 \mathrm{~m}$. Dust on cellulose filter, obtained from meltwater. (a) Dust particle (55 $\mu \mathrm{m}$ across) and (b) its associated EDS spectra. (c) Dust coated with a thin layer of gold prior to examination in the SEM (scale bar is $10 \mu \mathrm{m}$ ) and (d) associated EDS spectra.

(GRIP) and Dome Fuji (Dome F; Antarctica) deep cores. Thorsteinsson and others (1997) analyzed the correlations between crystal size, $\delta^{18} \mathrm{O}$ and impurities in the GRIP core and demonstrated that grain size was larger in warm interstadial periods, grain growth was slower during the Wisconsin period, and fine-grained ice was found where calcium and chloride concentrations exceeded 12 and 20 ppb, respectively.

In a comprehensive study of crystal texture and fabric in the Dome F core, Azuma and others (1999) found that crystal size (defined as equivalent area diameter) increases steadily with depth over the $2500 \mathrm{~m}$ core, with notable exceptions at five discrete depths, and that crystal size is positively correlated within the oxygen isotope levels. Further, the Dome F layers with smaller than expected crystals had calcium and chloride concentrations of $>40$ and $>100 \mathrm{ppb}$, respectively (Watanabe and others, 1999).

Because the GRIP and Dome F cores come from different geographical locations than the Vostok core, it is not as straightforward to compare their crystal orientations. Fabric develops in response to the local state of stress. At a dome, the vertical compression is accompanied by horizontal extension in all directions, producing a single-maximum fabric. Although the GRIP coring location was at the summit of Greenland, it was also on a dome, hence the shallower ice is primarily under vertical compression and characterized by a single maximum. Simple shear (pure shear plus rigid-body rotation) is caused by glaciers moving over local variations in topography and by substratum debris, but occurs well above the substratum in most cases (Alley, 1992; Thorsteinsson and others, 1997; personal communication from R.B. Alley, 2006). It also results in a vertical single-maximum fabric (Alley, 1992). Thus in both the GRIP and Dome $F$ cores, the $c$ axis orientation (measured with optical methods) develops from random near the surface to a strong single maximum at depth (Thorsteinsson and others, 1997; Azuma and others, 1999). At an ice divide or a location with significant horizontal flow, such as Vostok station, the dominant mode of deformation is pure shear, vertical compression plus uniaxial horizontal tension (Paterson, 1994). Pure shear can be resolved into principal stresses that are inclined to the surface, and results in a girdle-type fabric. In the Vostok core, the predominant girdle-type fabric makes the presence of a single-maximum fabric in the fine-grained layers above $3450 \mathrm{~m}$ (the D layer) notable. 


\subsection{Possible explanations for microstructural variations}

There are several mechanisms capable of limiting grain growth in specific regions of a core: migration recrystallization, polygonization and boundary pinning. Alley and others (1995) discuss in detail how $c$ axis fabrics can be used to determine which of these is most responsible for limiting grain growth in a given core section. Below, we use a similar analysis, expanded to include the use of a axis information, to determine the cause of microstructural variations in the vostok core.

\subsubsection{Recrystallization}

Slower than expected growth in mean grain area, and hence small grain size, can be caused by two recrystallization mechanisms, both of which have an effect on the fabric. First, nucleation and growth of strain-free grains at the expense of older, larger-strained grains containing multiple dislocations, sometimes known as migration recrystallization, is often found near the bottom of cores where it is favored by high strain energy and warmer temperatures. Migration recrystallization has produced both ring and multi-maxima $c$ axis fabrics in laboratory ice (Budd and Jacka, 1989), but, in nature, the fabric resulting from migration recrystallization probably depends on that of the preceding (shallower) ice as well as on the local state of stress. Migration recrystallization is most likely to take place where the ice temperature is $\geq-10^{\circ} \mathrm{C}$ and, once established, to extend to the bottom of the meteoric ice (Alley, 1988). Temperatures in the Vostok core do not reach $-10^{\circ} \mathrm{C}$ until approximately $3300 \mathrm{~m}$ (see Fig. 1). At 2874 m, where the first $B$ layer is noted $\left(B_{1}\right.$ in Fig. 1$)$, temperatures are close to $-20^{\circ} \mathrm{C}$. Further, this $\mathrm{B}$ layer and that at $3321 \mathrm{~m}$ are discrete and followed by A layers. Even at $3416 \mathrm{~m}$, where the temperature is above $-10^{\circ} \mathrm{C}$, we do not see the interpenetrating grains that are symptomatic of migration recrystallization (Fig. 2). When drilling had reached 2083 m, De La Chapelle and others (1998) determined that no migration recrystallization had taken place in the Vostok core. Now with specimens available from the complete core, we have found no evidence of migration recrystallization as deep as $3416 \mathrm{~m}$.

Second, polygonization (or rotation recrystallization) might explain the lack of an increase in grain size despite increasing depth and age because it involves the conversion of large grains into multiple smaller ones (Alley and Woods, 1996; Gow and others, 1997; De La Chapelle and others, 1998). In the characteristic A-type layers, polygonization would cause a widening of the vertical girdle over that which would otherwise be expected (De La Chapelle and others, 1998). De La Chapelle and others (1998) compare the fabric at $2080 \mathrm{~m}$ in Vostok ice to that produced using a VPSC model (the latter is much stronger), and conclude that polygonization has taken place in the Vostok core. In the misorientation distribution histograms for Vostok specimens from the $\mathrm{A}$ layers (1201, 1500, 2082, 2749, 3300, 3311 and $3329 \mathrm{~m}$ ) (Fig. 6), there are peaks in the $1-10^{\circ}$ range in the correlated data (between adjacent grains) that deviate from the overall fabric at these depths (seen in the uncorrelated data). This finding supports the theory that polygonization may have taken place in these Vostok A layers. This in turn means that the average grain size in these layers might actually be less than normal grain growth would cause. It does not, however, account for the especially fine-grained B layers.
The misorientations are largely $<40^{\circ}$ in the B-layer specimens and this is reasonable for the strong singlemaximum ice because the misorientations between grains with a strong preferred orientation should be relatively low. These specimens do not, however, exhibit an excess of very low misorientation angles between adjacent grains (compared with uncorrelated data) that would suggest polygonization. Therefore, neither migration recrystallization nor polygonization is likely to be the explanation for our B layers.

\subsubsection{Impurities: dust}

Dust levels are typically much higher at Vostok during glacial periods than interglacial periods, due to increased aridity and surface winds in the desert source regions, reduced atmospheric moisture and greater aerosol fallout, and to changes in atmospheric circulation (Jouzel and others, 1996; Petit and others, 1999). Consistent with this, Table 2 shows that the dust concentration is relatively high at $399 \mathrm{~m}$ (the end of the LGM), $2081 \mathrm{~m}$ (the previous ice age), $2875 \mathrm{~m}$ (glacial stage 8), $3321 \mathrm{~m}$ (glacial stage 12) and $3401 \mathrm{~m}$ (glacial stage 14) (Petit and others, 1999; Simões and others, 2002).

It has been shown both theoretically and empirically that inert second-phase particles inhibit grain growth and grainboundary migration in polycrystalline materials, including ice (Dunn and Walter, 1966; Gow and Williamson, 1976). Indeed, grain sizes are often found to be smaller in visually dirty ice than in clean ice of the same age (Gow and Williamson, 1976; Duval and Lorius, 1980). Initially, a causal relationship was drawn between the increase in particle concentration and the decrease in grain size across the Holocene-Wisconsin boundary in several ice cores (Koerner and Fisher, 1979). Later, however, two separate groups (Duval and Lorius, 1980; Alley and others, 1986b) compared the intrinsic driving force for grain growth with the drag force from particles in ice. Alley and others (1986b) concluded that at the particle concentrations present, the particles had little effect on grain growth in typical clean glacier ice. Even in visibly dirty glacier ice, the higher particle concentration does not always fully explain decreases in grain growth rate. For example, in the $1412.3 \mathrm{~m}$ Byrd (Antarctica) ice ash band, particles $4 \mu \mathrm{m}$ in radius (modal value) were found in a region where the grain radius averaged $1 \mathrm{~mm}$. Based on these values, Alley and others (1986b) calculated that the particles should reduce grain growth rates by $11 \%$. However, this did not fully explain the small grain sizes present. Therefore dissolved impurities were also thought to contribute to the decreased grain growth rate.

That higher particle concentration alone does not explain the changes in microstructure in glacial periods is supported by our observations of the fine-scale grain-size variations in the 3321.765-3321.805 $\mathrm{m}$ specimen. First, the dark bands do not fully account for the finer-grained layers present, as the extremely fine-grained layers are thicker than the dark bands. Second, the whole section (even the larger-grained portion and the ice which is relatively clear) exhibits slower than normal grain growth, which deviates significantly from the fit. Third, the entire $3321 \mathrm{~m}$ specimen is characterized by a single-maximum fabric. Hence the entire specimen is classified as a B-type layer, and there is no evidence that ash bands play a significant role in the microstructure. The cause of the differences in grain size within this depth range may be the differences in soluble impurity content. 


\subsubsection{Impurities: soluble}

Soluble impurities inhibit grain-boundary migration and limit grain growth by segregating to the grain boundaries, where boundary velocity is then controlled by the rate of diffusion of impurity atoms (Wolff and Paren, 1984). Boundary mobility is inversely related to solute concentration, but the strength of the relationship varies with the solute (Wolff and Paren, 1984). Different solutes have different critical concentrations at which they cause boundary mobility to shift from the high to low regime. The grain-boundary migrationlimiting effect of solutes is most noted in doped laboratory ice where the soluble ions exist in high concentrations (Iliescu and others, 2003). It has been found that increasing sulfuric acid concentration from 70 to 170 ppb decreases the grainboundary mobility (and significantly retards the nucleation of new grains) (Iliescu and others, 2003).

Many attempts have been made to correlate grain size with various soluble impurities in actual ice cores, occasionally with conflicting results. Based on a study of crystal size variations in two Antarctic cores (Dome C and Vostok), Petit and others (1987) suggested a temperature memory effect, where crystal growth is driven primarily by a built-in 'memory' of the surface temperature at the time of deposition. The 'memory effect' theory is controversial, but it is interesting to note that, in support of their theory, the authors cite evidence to discount the effect of sodium, sulfates and nitrates on variations in grain growth. However, Alley and others (1986b) argue that the reduction in grain growth rate and concomitant reduction in grain size in Wisconsin ice from Dome C, Antarctica, is due to impurity drag resulting from the high concentrations of soluble impurities including sulfate, chloride and sodium. Similarly, Langway and others (1988) found that reduced grain growth in Wisconsin ice from the Dye 3 (Greenland) core was correlated with higher than usual sulfate and chloride ion concentrations. Paterson later reviewed the characteristics of glacial-period ice from a number of cores and concluded that both chloride and sulfate impede grain-boundary migration and grain growth (Paterson, 1991).

The ion concentrations in the shallower depths in Table 2 could be compared with those reported by Legrand and others (1988, figs 1-3). The higher cation concentrations in the 650 and $1849 \mathrm{~m}$ samples are attributable to the $20 \%$ instrument drift discussed earlier. In the $399 \mathrm{~m}$ sample, we measured cation levels about an order of magnitude higher, and $\mathrm{Cl}^{-}$and $\mathrm{NO}_{3}{ }^{-}$levels three to five times higher, than reported by Legrand and others (1988). Our values are not unreasonable, however, since age and texture already suggest that this ice dates from the LGM. Other significant variations between our ion concentrations and those of Legrand and others (1988) are as follows: $\mathrm{K}^{+}$levels more than an order of magnitude higher at 650 and $1849 \mathrm{~m}$; and $\mathrm{NO}_{3}{ }^{-}$values more than an order of magnitude higher at 1200, 1500 and, particularly, $2082 \mathrm{~m}$. Yet neither these high ion concentrations, nor those noted at $399 \mathrm{~m}$, correlate with any noticeable variations in the microstructure of these samples. Instead, the $\{0001\}$ pole figures (Fig. 6) reveal a steady development (within the limitations of our data) from 399 to $2082 \mathrm{~m}$ of the vertical-girdle fabric that is consistent with previous findings for this part of the Vostok core (Pimienta and others, 1988; Lipenkov and others, 1989).

Let us now turn to an examination of the deeper $(>2700 \mathrm{~m})$ specimens with fine grain size, namely 2874 , 3321 and $3399 \mathrm{~m}$. In light of the work of Alley and others (1986b) and Paterson (1991), examination of the $\mathrm{Na}^{+}, \mathrm{Cl}^{-}$ and $\mathrm{SO}_{4}{ }^{2-}$ concentration data (Table 2) in particular shows no consistent correlation between high levels of these impurities and fine grain size. The $(10-50 \mu \mathrm{m})$ impurities found in the lattice, composed primarily of Si and $\mathrm{Al}$, with some combination of $\mathrm{K}, \mathrm{Mg}$, Fe and sometimes $\mathrm{Na}, \mathrm{Ca}, \mathrm{Cl}$ and $\mathrm{S}$, are most likely primarily aluminosilicates (e.g. biotite, or black mica, $\left.\mathrm{K}(\mathrm{Mg}, \mathrm{Fe})_{3}\left(\mathrm{AlSi}_{3} \mathrm{O}_{10}\right)(\mathrm{OH})_{2}\right)$. This is consistent with the higher terrestrial dust input and particle sizes during glacial periods (Legrand, 1988; Petit and others, 1990). These types of particle are found in many samples, including interglacial samples, where they tend to be smaller and fewer in number, and are not associated in location with grain boundaries or triple junctions. Typical glacial-period ice from Antarctica (i.e. Byrd Station) tends to be marked by increases in aluminium and silicon (from aluminosilicate dust), but the presence of the large particulates does not seem to be directly related to grain size.

However, in the glacial layers, there is also a positive correlation between fine grain size and a single-maximum fabric and high concentrations of cations, particularly $\mathrm{Ca}^{+}$ (as measured with ion chromatography). As noted earlier, the high impurity concentration, small grain size and strong fabric are often found together in glacial ice, but in the Vostok core two additional differences between glacial and interglacial ice are present. First, there is not only a strong fabric in the glacial ice, but also a different fabric (single maximum vs vertical girdle) to be explained. Second, in the grain boundaries of these samples, $\mathrm{Ca}, \mathrm{Cl}$ and sometimes $\mathrm{K}$ were found together in white spots of unprecedented number and size $(5-10 \mu \mathrm{m})$. While the EDS does not produce quantitative results, the $\mathrm{Ca}$ peak was generally significantly higher than the $\mathrm{Cl}$ peak (Fig. 11b). Ice from the Vostok area is known to have calcium concentrations comparable to those in Greenland, which increases significantly during glacial periods (Paterson, 1991). Hence it is not surprising to find calcium in these specimens.

However, it is unusual to find concentrations of calcium on the grain boundaries. The $\mathrm{Ca}$ found in the grain boundaries could be associated with small insoluble calcium particles (e.g. plagioclases $\left((\mathrm{Na}, \mathrm{Ca})(\mathrm{SiAl})_{4} \mathrm{O}\right)$ (Laj and others, 1997)), or arise from soluble calcium-containing compounds such as calcium carbonate $\left(\mathrm{CaCO}_{3}\right)$ and calcium sulfate $\left(\mathrm{CaSO}_{4}\right)$. Soluble and insoluble Ca-containing impurities generally have different sources, and a low correlation in their occurrence (Laj and others, 1997). Only soluble Ca would be detected by ion chromatography, and there was a higher $\mathrm{Ca}^{+}$ion concentration found in glacial-period specimens. This suggests soluble calcium sources, i.e. $\mathrm{CaCO}_{3}$ and $\mathrm{CaSO}_{4}$. Calcium carbonate is usually observed in desert aerosols, which contribute especially to Ice Age ice, when continental margins are more exposed by a drop in sea level and wind transport is more effective. In glacial period, is Ca (and $\mathrm{Mg}$ ) also found associated with the nitrate and sulfate anions (Legrand and others, 1988; Laj and others, 1997). Not only is $\mathrm{CaSO}_{4}$ fairly common in several solid phases, i.e. gypsum and anhydrite, but it, like $\mathrm{CaNO}_{3}$, may be formed in the atmosphere from the reaction between $\mathrm{CaCO}_{3}$ and acidic gases $\left(\mathrm{SO}_{4}\right.$ and $\left.\mathrm{NO}_{x}\right)$ (Legrand and others, 1988). Both $\mathrm{CaCO}_{3}$ and $\mathrm{CaSO}_{4}$ are very soluble and could easily contribute the $\mathrm{Ca}^{+}$ions found on the grain boundaries. However, the calcium on the grain boundaries could also be associated with very small insoluble particles, particularly when found with $\mathrm{Na}$, Si and Al. 
The $\mathrm{Cl}$ and $\mathrm{K}$ found in grain-boundary white spots are also easily explained. Sea salt is very soluble and is the main source of $\mathrm{Cl}$ in ice (Legrand, 1988). Soluble potassium in ice cores comes largely from sea salt and clays, as other terrestrial sources such as $\mathrm{K}$-feldspars $\left(\mathrm{KAISi}_{3} \mathrm{O}_{8}\right)$ and mica $\left(\mathrm{KAI}_{2}\left(\mathrm{AlSi}_{3} \mathrm{O}_{10}\right)(\mathrm{OH})_{2}\right)$ are less soluble. Clay (and mica) content is independent of temperature, but K-feldspars are more abundant during cold stages (Laj and others, 1997). Hence, it is not surprising to see K occasionally contributing to the white spots found on the grain boundaries of our glacial ice.

To summarize, as Ca was often present in the grainboundary impurities in the B layers (but never in the A layers), and as it was found in higher ion concentration there, and also because high concentrations of $\mathrm{Ca}$ are a documented aspect of glacial ice, it appears that $\mathrm{Ca}$ is playing an important part in limiting grain growth in those layers. It is also worth noting that of the two most prevalent constituents, Ca has more than twice the atomic radius of $\mathrm{Cl}$ $(180 \mathrm{pm}$ vs $79 \mathrm{pm})$ suggesting that interactions of the large Ca atoms with the imperfect lattice at the grain boundaries may be affecting grain-boundary migration and grain growth.

It is interesting to note that $\mathrm{Ca}$ in the lattice and grain boundaries was found only in the very fine-grained layers of the $3321 \mathrm{~m}$ specimen, and not in the larger-grained layer in its middle (3321.785-3321.802 $\mathrm{m})$. The cation data for the $3321 \mathrm{~m}$ specimen, showing a relatively significant $\mathrm{Ca}^{+}$ content (409 ppb), were measured in samples cutting across all three layers. Although Ca was found in large particulates in the lattice in each layer of the $3321 \mathrm{~m}$ sample, none was found in the grain boundaries of the larger-grained middle layer. Perhaps this explains the variation in grain size within this specimen. It would not explain why even the grains in the middle layer are not as large as expected, but their confinement between the two fine-grained layers might.

\subsubsection{Influence of orientation on grain growth}

The statistically high predominance of certain orientations in a polycrystal also affects grain growth. Here, some clarification of terminology is necessary, because both metallurgical and glaciological literature is referenced. First, the terms crystal and grain are used interchangeably for polycrystalline ice. Second, the crystallographic orientation of grains in an aggregate, known as texture in other materials, is referred to as fabric in geology and glaciology. In materials science, the limiting effect of a strong preferred orientation on grain-boundary migration is known as 'texture-pinning'. This same terminology is used herein, to mean that a strong fabric (preferred orientation) pins or limits the texture (grain size). Boundary structure, i.e. the lattice site coincidence between the adjacent grains and the orientation of the boundary with respect to the lattices, influences boundary mobility. Two grains with similar orientations share a low-angle grain boundary, which has less energy and mobility than a high-angle boundary (Humphreys and Hatherly, 1995). Grain-boundary migration, which involves diffusion processes across the boundary, is required for grain growth. When a high percentage of the grain boundaries in a polycrystal are of the less mobile, low-angle type, grain-boundary migration, and hence grain growth, is slower than it would be if the specimen were isotropic. Texture pinning has been observed in several metals. For example, measurements on bicrystals of zinc have shown that: the mobility of low-angle grain boundaries $\left(<10^{\circ}\right)$ is significantly lower than that of high-angle boundaries; mobility increases with misorientation; and the activation energy for low-angle boundary migration is higher than that for high-angle boundaries (Humphreys and Hatherly, 1995).

A similar phenomenon may take place in ice. Initially, after pore close-off, meteoric ice is fine-grained and isotropic. Compression from the overburden tends to produce a single-maximum fabric in the ice sheet, due to slip on the basal plane, which rotates the $c$ axes toward the compression axis (Alley, 1988). At Vostok, the added factor of uniaxial tension leads to the development of a verticalgirdle fabric.

Over time, a vertical-girdle fabric evolves due to the combined effects of basal slip under the effects of horizontal flow and uniaxial tension, and orientation preferred grain growth. Grains with higher-angle grain boundaries have a boundary mobility advantage. This means that, depending on their size advantage or lack thereof, they will grow or shrink compared with their low-angle grain-boundary neighbors. Where higher-angle boundaries exist in the polycrystal, larger grains consume smaller ones, and the average grain size increases.

An example of this can be found in the recrystallization of metals. Li and Baker (2005) found that the primary recrystallization of cold-rolled, high purity nickel at $400^{\circ} \mathrm{C}$ resulted in a weak cube texture with a lesser $\{124\}\langle 21-1\rangle$ component. After secondary recrystallization, only the $\{124\}\langle 21-1\rangle$; oriented grains remained. These outgrew grains with other orientations and consumed them during a growth selection process driven by advantages in grain-boundary energy or mobility. Abbruzzese and Lücke (1986) developed a model for such texture-controlled grain growth. They found that the simple model of a critical radius separating grains that grow from those that shrink fails when orientation is introduced as a factor. Instead, different orientations have different critical radii and, in the presence of preferred orientations, the grain growth law expressed in Equation (2) no longer holds.

\subsubsection{The relationship between solutes and orientation}

Finally, the relationship between solutes and boundary geometry adds a third factor to boundary mobility. Humphreys and Hatherly (1995) go so far as to argue that the orientation dependence of grain-boundary mobility arises from an orientation dependence of solute segregation to the boundary rather than from an intrinsic structure dependence of grain-boundary mobility. In some metals there is evidence that the orientation dependence of mobility decreases at both very high and very low solute concentrations. In zinc, for instance, there is a window in impurity content in which an orientation dependence of mobility is observed (Sursaeva and others, 1976; Gottstein and Shvindlerman, 1992).

The B layers in the Vostok core are probably the result of a complex interplay of solute and texture pinning. They are distinguished by the presence of abnormally high Ca levels in the grain boundaries. This limits the mobility of the grain boundary (which in itself limits grain growth) and means that high-angle boundaries lack the advantage that they would otherwise have over low-angle boundaries. If this is the case, there is no reason for grains with divergent $c$ axes 
(i.e. on the higher-angle parts of a vertical girdle) to grow at the expense of the small grain-boundary angle grains near the center of the $\{0001\}$ pole figure. This preserves both the smaller average grain size and the single-maximum fabric, which itself contributes to further limiting grain growth through texture pinning. Hence, one observes both smaller grains and a strong single-maximum fabric in the B layers. Neither migration recrystallization nor polygonization has taken place in the B zones, and the abnormally high degree of flattening in the $B$ layers is the alternative to polygonization in the face of further strain after a strong preferred fabric has developed.

\section{CONCLUSIONS}

In the Vostok 5G core, two distinctly different types of microstructure, referred to as $\mathrm{A}$ and $\mathrm{B}$, after Lipenkov and Barkov (1998), distinguish interglacial from glacial ice. Analysis of specimens from 97 to $3416 \mathrm{~m}$ in the Vostok 5G core leads to the following conclusions:

1. The characteristic fabric of the Vostok core, the vertical girdle, is noted beginning at $1201 \mathrm{~m}$, and strengthens with depth in the (interglacial) A layers. That this correlation between fabric strength and depth is not more pronounced (and that the actual fabric is not nearly as strong as predicted by models (De La Chapelle and others, 1998)) suggests that polygonization may be taking place in the A layers, as also shown by the high number of very low-angle grain boundaries $\left(1-10^{\circ}\right)$ in these layers.

2. In the A layers, which are associated with interglacial periods, grain area increases linearly with time. Grain boundaries are typically straight, grains are very regular, and flattening is correlated only weakly with depth. As deep as $3416 \mathrm{~m}$, migration recrystallization has not taken place.

3. Dust content is higher in ice from glacial stages (personal communication from V. Lipenkov, 2004), and specifically it is higher in the vicinity of B-layer samples 2874, 3321 and $3399 \mathrm{~m}$. As mentioned in section 1, a number of glaciologists have concluded that high dust content, while positively correlated with small grain size, is not its cause, and the large particles observed here were always in the lattice, never in the grain boundaries. Further, the $3321 \mathrm{~m}$ specimen had visible dark bands that did not correlate with the regions of fine grain size. It is still possible, however, that particulates play an indirect role by supplying a soluble impurity.

4. Unusual and significant occurrences of $\mathrm{Ca}$ are found on the grain boundaries in the $B$ layers and are unique to these layers. This may explain why the B layers have an abnormally small grain size, which is far less than that suggested by the grain-growth fit seen in A layers between 97 and $3399 \mathrm{~m}$, and a strong single-maximum fabric. Flattening, also indicative of limited grain growth, is also more pronounced in the $B$ layers. These differences are visible within $4 \mathrm{~cm}$ of vertical distance at 3321.765-3321.805 m, where there is a central layer of larger and more equiaxed grains in which no grainboundary Ca was found.
5. The B zones can be explained by a reduction in grainboundary energy and hence grain-boundary mobility, where the presence of soluble Ca above some critical concentration decreases both grain-boundary mobility and its misorientation dependence, leading to a singlemaximum texture. The grain-boundary calcium may come from large particulates containing this element in a soluble form, i.e. $\mathrm{CaSO}_{4}$ or $\mathrm{CaNO}_{3}$, which, as continental dust, are found in greater abundance in glacial periods.

6. Despite fine-scale variations in grain size, $3321 \mathrm{~m}$ is a B (glacial) zone. The cause of the differences in grain size within this depth range may be the differences in the amount of $\mathrm{Ca}$ present in the fine- and larger-grained layers. $\mathrm{Ca}$ is present in particulates throughout the specimen, but was also found in lattice white spots of the very fine-grained layers.

7. Stratum C (3310-3370 m) includes both A-type (3311 and $3329 \mathrm{~m})$ and B-type $(3321 \mathrm{~m})$ layers and may actually represent $A_{3}$ (extending to at least $3311 \mathrm{~m}$ ), $B_{3}$ (extending from $\mathrm{A}_{3}$ to at least $3321 \mathrm{~m}$ ) and $\mathrm{A}_{4}$ (beginning by $3329 \mathrm{~m}$ ).

8. The ice at $3416 \mathrm{~m}$ probably represents interglacial stage 15. It falls between 3405 and $3440 \mathrm{~m}$, glacial stages 14 and 16 identified by previous authors (Simões and others, 2002; Salamatin and others, 2004), and has the characteristics of an interglacial layer, i.e. large grains and a vertical-girdle fabric.

\section{ACKNOWLEDGEMENTS}

We thank the US National Ice Core Laboratory for making available the specimens for this study, and V. Lipenkov of the Arctic and Antarctic Research Institute, St Petersburg, Russia, for generously sharing his data, expertise and insights. We also acknowledge the significant help of G. Hargreaves of NICL and J. Quigley of Dartmouth. This research was supported by the US National Science Foundation grant OPP-0440523. The views and conclusions contained herein are those of the authors and should not be interpreted as necessarily representing official policies, either expressed or implied, of the National Science Foundation or the US Government.

\section{REFERENCES}

Abbruzzese, G. and K. Lücke. 1986. A theory of texture controlled grain growth: I. Derivation and general discussion. Acta Metall. Mater., 34(5), 905-914.

Alley, R.B. 1988. Fabrics in polar ice sheets: development and prediction. Science, 240(4851), 493-495.

Alley, R.B. 1992. Flow-law hypotheses for ice-sheet modeling. J. Glaciol., 38(129), 245-256.

Alley, R.B. and G.A. Woods. 1996. Impurity influence on normal grain growth in the GISP2 ice core, Greenland. J. Glaciol., 42(141), 255-260.

Alley, R.B., J.H. Perepezko and C.R. Bentley. 1986a. Grain growth in polar ice: I. Theory. J. Glaciol., 32(112), 415-424.

Alley, R.B., J.H. Perepezko and C.R. Bentley. 1986b. Grain growth in polar ice: II. Application. J. Glaciol., 32(112), 425-433.

Alley, R.B., A.J. Gow and D.A. Meese. 1995. Mapping c-axis fabrics to study physical processes in ice. J. Glaciol., 41(137), 197-203.

Azuma, N. and A. Higashi. 1985. Formation processes of ice fabric pattern in ice sheets. Ann. Glaciol., 6, 130-134. 
Azuma, N. and 6 others. 1999. Textures and fabrics in the Dome $\mathrm{F}$ (Antarctica) ice core. Ann. Glaciol., 29, 163-168.

Baker, I., D. Cullen and D. Iliescu. 2003. The microstructure location of impurities in ice. Can. J. Phys., 81, 1-9.

Barkov, N.I. and V.Ya. Lipenkov. 1984. Kolichestvennaia Kharakteristika struktury l'da do glubiny $1400 \mathrm{~m}$. v raione stantsii Vostok v Antarktide [Quantitative characteristics of ice structure, down to $1400 \mathrm{~m}$ in the Vostok Station area, Anarctica]. Mater. Glyatsiol. Issled. 51, 178-186

Bate, P.S., R.D. Knutsen, I. Brough and F.J. Humphreys. 2005. The characterization of low-angle boundaries by EBSD. J. Microsc., 220(1), 36-46.

Beck, P.A. 1954. Annealing of cold worked metals. Adv. Phys., 3(11), 245-324.

Budd, W.F. and T.H. Jacka. 1989. A review of ice rheology for ice sheet modelling. Cold Reg. Sci. Technol., 16(2), 107-144.

Castelnau, O., G.R. Canova, R.A. Lebensohn and P. Duval. 1997. Modelling viscoplastic behavior of anisotropic polycrystalline ice with a self-consistent approach. Acta Mater., 45(11), 4823-4834.

Cullen, D. and I. Baker. 2000. Correspondence. The chemistry of grain boundaries in Greenland ice. J. Glaciol., 46(155), 703-706.

Cullen, D. and I. Baker. 2001. Observation of impurities in ice. Microsc. Res. Tech., 55(3), 198-207.

De La Chapelle, S., O. Castelnau, V. Lipenkov and P. Duval. 1998. Dynamic recrystallization and texture development in ice as revealed by the study of deep ice cores in Antarctica and Greenland. J. Geophys. Res., 103(B3), 5091-5105.

Dunn, C.G. and J.L. Walter. 1966. Secondary recystallization. In Margolin, H., ed. Recrystallization, grain growth and textures. Metals Park, OH, American Society for Metals, 461-521.

Duval, P. and C. Lorius. 1980. Crystal size and climatic record down to the last ice age from Antarctic ice. Earth Planet Sci. Lett., 48(1), 59-64.

Gottstein, G. and L.S. Shvindlerman. 1992. On the true dependence of grain boundary migration rate on driving force. Scripta Metall. Mater., 27(11), 1521-1526.

Gow, A.J. 1969. On the rates of growth of grains and crystals in South Polar firn. J. Glaciol., 8(53), 241-252.

Gow, A.J. and T. Williamson. 1976. Rheological implications of the internal structure and crystal fabrics of the West Antarctic ice sheet as revealed by deep core drilling at Byrd Station. CRREL Rep. 76-35.

Gow, A.J. and 6 others. 1997. Physical and structural properties of the Greenland Ice Sheet Project 2 ice cores: a review. J. Geophys. Res., 102(C12), 26,559-26,575.

Humphreys, F.J. and M. Hatherly. 1995. Recrystallization and related annealing phenomena. Oxford, etc., Pergamon Press.

Iliescu, D., I. Baker and X. Li. 2003. The effects of sulfuric acid on the creep, recrystallization, and electrical properties of ice. Can. J. Phys., 81(1-2), 395-400.

Iliescu, D., I. Baker and H. Chang. 2004. Determining the orientation of ice crystals using electron backscatter patterns. Microsc. Res. Tech., 63, 183-187.

Jouzel, J. and 6 others. 1987. Vostok ice core: a continuous isotope temperature record over the last climatic cycle $(160,000$ years). Nature, 329(6138), 403-408.

Jouzel, J. and 14 others. 1996. Climatic interpretation of the recently extended Vostok ice core records. Climate Dyn., 12(8), 513-521.

Koerner, R.M. and D.A. Fisher. 1979. Discontinuous flow, ice texture, and dirt content in the basal layers of the Devon Island ice cap. J. Glaciol., 23(89), 209-222.

Laj, P. and 7 others. 1997. Distribution of $\mathrm{Ca}, \mathrm{Fe}, \mathrm{K}$, and $\mathrm{S}$ between soluble and insoluble material in the Greenland Ice Core Project ice core. J. Geophys. Res., 102(C12), 26,615-26,623.

Langway, C.C., Jr, H. Shoji and N. Azuma. 1988. Crystal size and orientation patterns in the Wisconsin-age ice from Dye 3, Greenland. Ann. Glaciol., 10, 109-115.
Legrand, M.R., C. Lorius, N.I. Barkov and V.N. Petrov. 1988. Vostok (Antarctica) ice core: atmospheric chemistry changes over the last climatic cycle (160,000 years). Atmos. Environ., 22(2), 317-331.

Li, J. and I. Baker. 2005. An EBSP study of directionally recrystallized cold-rolled nickel. Mater. Sci. Eng., 392(1-2), 8-22.

Lipenkov, V.Ya. and N.I. Barkov. 1998. Stroyeniye Antarkticheskogo lednikovogo pokrova po rezul'tatam glubokogo bureniya na stantsii Vostok [Internal structure of the Antarctic ice sheet as revealed by deep core drilling at Vostok station]. In Lake Vostok study: scientific objectives and technological requirements. International workshop. Abstracts. St Petersburg, Arctic and Antarctic Research Institute, 31-35.

Lipenkov, V.Ya., N.I. Barkov, P. Duval and P. Pimienta. 1989. Crystalline texture of the $2083 \mathrm{~m}$ ice core at Vostok Station, Antarctica. J. Glaciol., 35(121), 392-398.

Lipenkov, V.Ya., O.A. Ryskin and N.I. Barkov. 1999. O svyazi mezhdu kolichestvom vozdushnykh vklyucheniy vo l'du i isloviyami I'doobrazovaniya [Relationship of number of air inclusions in ice with ice formation conditions]. Mater. Glyatsiol. Issled. 86, 75-92.

Obbard, R., I. Baker and D. Iliescu. 2006a. Correspondence. Grain boundary grooving in ice in a scanning electron microscope. J. Glaciol., 52(176), 169-172.

Obbard, R., I. Baker and K. Sieg. 2006b. Using electron backscatter diffraction patterns to examine recrystallization in polar ice sheets. J. Glaciol., 52(179), 546-557.

Paterson, W.S.B. 1991. Why ice-age ice is sometimes "soft". Cold Reg. Sci. Technol., 20(1), 75-98.

Petit, J.R., P. Duval and C. Lorius. 1987. Long-term climatic changes indicated by crystal growth in polar ice. Nature, 326(6108), 62-64.

Petit, J.R., L. Mounier, J. Jouzel, Y. Korotkevich, V.M. Kotlyakov and C. Lorius. 1990. Palaeoclimatological and chronological implications of the Vostok core dust record. Nature, 343(6253), 56-58.

Petit, J.R. and 7 others. 1998. Predvaritel'nyye rezul'taty issledodovaniy ledyanogo kerna so stantsii Vostok do glubiny $3623 \mathrm{~m}$ [Preliminary investigations and implications from the $3623 \mathrm{~m}$ Vostok deep ice core studies]. In Lake Vostok Study: scientific objectives and technological requirements. International workshop, Abstracts. St Petersburg, Arctic and Antarctic Research Institute.

Petit, J.R. and 18 others. 1999. Climate and atmospheric history of the past 420,000 years from the Vostok ice core, Antarctica. Nature, 399(6735), 429-436.

Pimienta, P., P. Duval and V.Y. Lipenkov. 1988. Mechanical behavior of ice along the $2040 \mathrm{~m}$ Vostok core, Antarctica. Ann. Glaciol., 10, 137-140.

Popkov, A.M., S.R. Verkulich, V.N. Masolov and V.V. Lukin. 1999. Seysmicheskiy razrez $v$ rayone stantsii Vostok (Antarktida) rezul'taty issledovaniy 1997 goda [Vertical seismic profiling at Vostok Station (Antarctica): results of studies in 1997]. Mater. Glyatsiol. Issled. 86, 152-159. [In Russian with English summary.]

Randle, V. and O. Engler. 2000. Introduction to texture analysis: macrotexture, microtexture and orientation mapping. Amsterdam, etc., Gordon and Breach.

Salamatin, A.N., R.N. Vostretsov, J.R. Petit, V.Ya. Lipenkov and N.I. Barkov. 1998. Geophysical and palaeoclimatic implications of the stacked temperature profile from the deep borehole at Vostok station, Antarctica. Mater. Glyatsiol. Issled. 85, 233-240. [In Russian.]

Salamatin, A.N., E.A. Tsyganova, V.Ya. Lipenkov and J.R. Petit. 2004. Vostok (Antarctica) ice-core time-scale from datings of different origins. Ann. Glaciol., 39, 283-292.

Simôes, J.C. and 7 others. 2002. Evidence of glacial flour in the deepest $89 \mathrm{~m}$ of the Vostok ice core. Ann. Glaciol., 35, 340-346. 
Sursaeva, V.G., A.V. Andreeva, C.V. Kopezky and L.S. Shvindlerman. 1976. Mobility of incline boundary (1010) in zinc. Fizika Metallov/Metallovedenie, 41, 1013.

Thorsteinsson, T., J. Kipfstuhl and H. Miller. 1997. Textures and fabrics in the GRIP ice core. J. Geophys. Res., 102(C12), $26,583-26,599$.
Watanabe, O., K. Kamiyama, H. Motoyama, Y. Fujii, H. Shoji and K. Satow. 1999. The palaeoclimate record in the ice core from Dome Fuji station, Antarctica. Ann. Glaciol., 29, 176-178.

Wolff, E.W. and J.G. Paren. 1984. A two-phase model of electrical conduction in polar ice sheets. J. Geophys. Res., 89(B11), 9433-9438.

MS received 9 March 2006 and accepted in revised form 29 October 2006 